University of Louisville

ThinkIR: The University of Louisville's Institutional Repository

\title{
Public health department perspectives on cervical and prostate cancer prevention in southeastern Kentucky.
}

Jordan Danielle Burns

University of Louisville

Follow this and additional works at: https://ir.library.louisville.edu/honors

Part of the Diseases Commons, and the Public Health Commons

\section{Recommended Citation}

Burns, Jordan Danielle, "Public health department perspectives on cervical and prostate cancer prevention in southeastern Kentucky." (2013). College of Arts \& Sciences Senior Honors Theses. Paper 7. http://doi.org/10.18297/honors/7

This Senior Honors Thesis is brought to you for free and open access by the College of Arts \& Sciences at ThinkIR: The University of Louisville's Institutional Repository. It has been accepted for inclusion in College of Arts \& Sciences Senior Honors Theses by an authorized administrator of ThinkIR: The University of Louisville's Institutional Repository. This title appears here courtesy of the author, who has retained all other copyrights. For more information, please contact thinkir@louisville.edu. 


\section{PUBLIC HEALTH DEPARTMENT PERSPECTIVES ON CERVICAL AND PROSTATE CANCER PREVENTION IN SOUTHEASTERN KENTUCKY}

By:

Jordan Danielle Burns

Submitted in partial fulfillment of the requirements

for Graduation summa cum laude

University of Louisville

Louisville, $\mathrm{KY}$

March 29, 2013 


\section{TABLE OF CONTENTS}

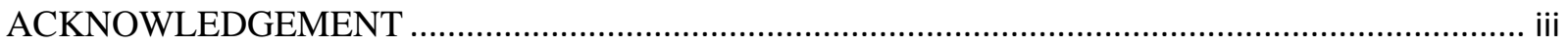

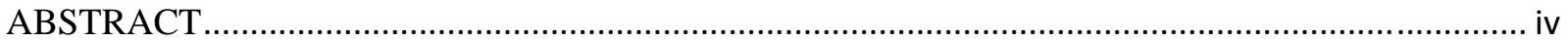

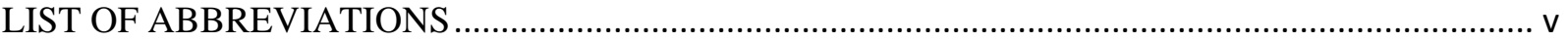

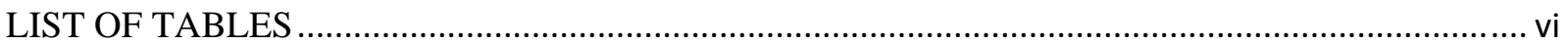

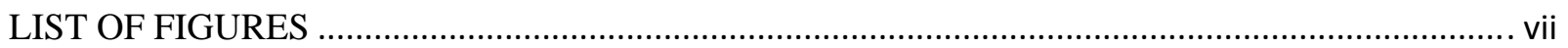

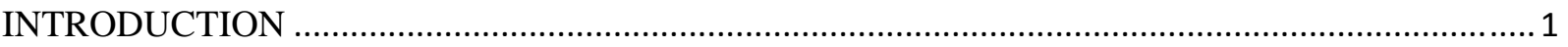

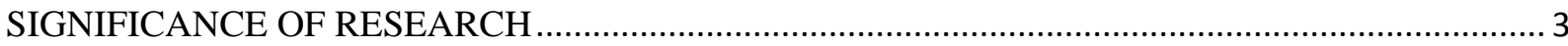

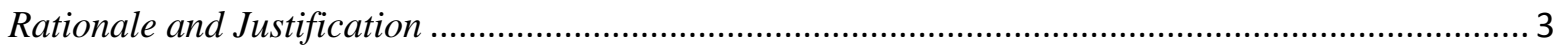

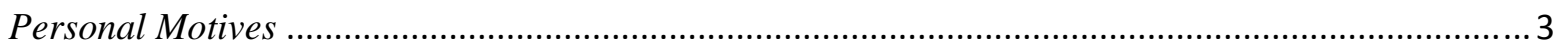

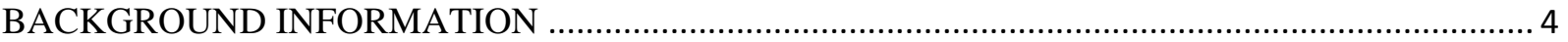

The Importance and Impact of Cancer Screening and Prevention .................................................. 4

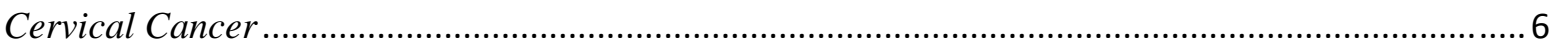

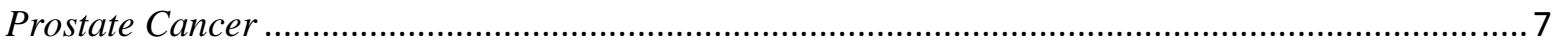

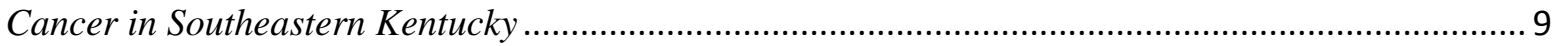

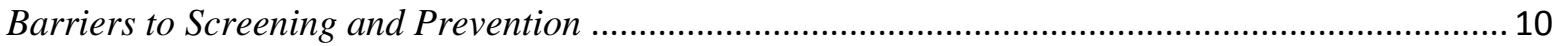

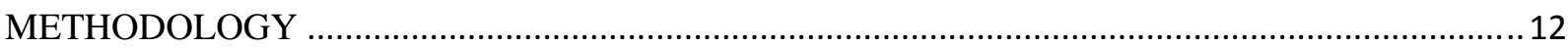

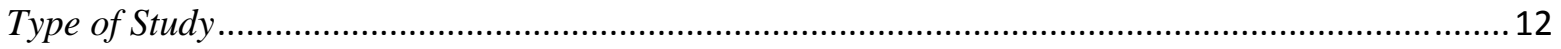

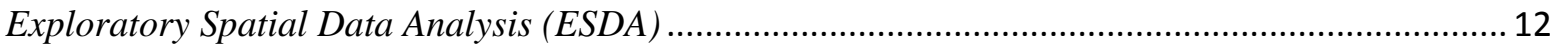

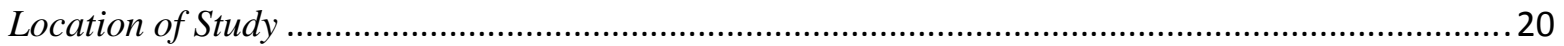

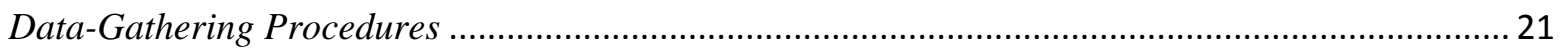

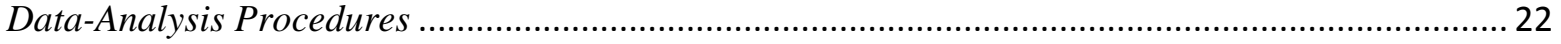

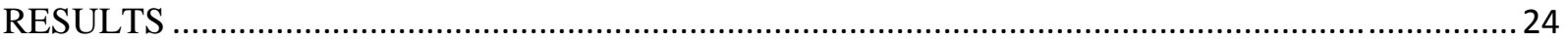

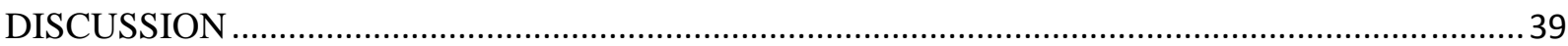

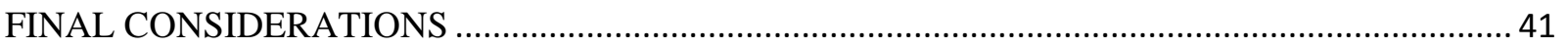

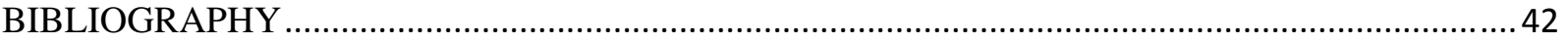

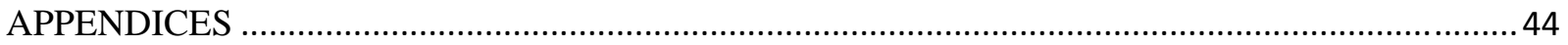




\section{ACKNOWLEDGEMENT}

I would like to thank those who made this research project possible, especially all of the directors, cancer program managers, nurse practitioners, and staff members of the Kentucky public health departments of Bell, Breathitt, Floyd, Johnson, Knox, Laurel, Magoffin, Martin, Pike, and Whitely Counties and of the Cumberland Valley and Kentucky River Districts. These men and women took time out of their busy schedules to set up phone interviews and to discuss their work in cancer screening and prevention. They were open to questions regarding both their successes and their challenges. It is very important to take action in communities in need, but it is also just as imperative to reflect on our strengths and weaknesses in order to improve.

I would also like to thank the faculty members at the University of Louisville who provided me with guidance and feedback throughout this process. Dr. Carol Hanchette of the Department of Geography and Geosciences served as my mentor, helped me to develop a plan of action, and counseled me in the use of basic Geographic Information Systems (GIS) and geostatistical methods. Dr. Christopher Tillquist of the Department of Anthropology and Dr. Thomas Riedel of the Department of Mathematics both served as faculty readers. Their input and suggestions were very valuable, from the initial proposal to the final product. 


\section{ABSTRACT}

This study compared and contrasted the screening and prevention methods and strategies utilized by public health departments in southeastern Kentucky for both cervical and prostate cancer. Special attention was paid to how such efforts have influenced decreases in mortality rates over the past two decades. The study used both geospatial methods, such as Exploratory Spatial Data Analysis (ESDA) and spatial autocorrelation, and qualitative methods in form of interviews. The interview data showed that Kentucky public health departments had strong cervical cancer screening and prevention programs, but did not focus on prostate cancer prevention. Successes in cervical cancer screening included the expansion of resources and services through the Breast and Cervical Cancer Treatment Program, community outreach, and an increase in transportation access. For prostate cancer, only two health departments had reported offering any type of services. Other counties attributed prostate prevention success to an increase in physicians in the area and the work of employers to encourage screenings. When these results were explored through further geospatial data analysis, there did not seem to be any major correlations between the interview data and clusters of incidence and mortality rate changes. The reasons for a decrease in mortality in cervical cancer are more evident than for prostate cancer, from the perspective of the health department. The key finding was that prostate cancer does not garner the public funding support that cervical cancer does. In order to discover the cause for prostate cancer mortality rate decrease in southeastern Kentucky, the public health department is not the ideal place to look. 


\section{LIST OF ABBREVIATIONS}

ANOVA - Analysis of Variance

BCCTP - Breast and Cervical Cancer Treatment Program

CDC - Centers for Disease Control and Prevention

DRE - Digital Rectal Exam

ESDA - Exploratory Spatial Data Analysis

FDA - Food and Drug Administration

HPV - Human Papilloma Virus

KCR - Kentucky Cancer Registry

LISA - Local Index of Spatial Autocorrelation

PSA - Prostate-Specific Antigen

SEER - Surveillance, Epidemiology, and End Results

STD - Sexually-Transmitted Disease

USPSTF - United States Preventive Services Task Force 


\section{LIST OF TABLES}

Table 1: Cervical Cancer 5-year Relative Survival by Stage at Diagnosis for 2002-2008, All Races, Female

Table 2: Prostate Cancer 5-year Relative Survival by Stage at Diagnosis for 2002-2008, All Races, Male 5

Table 3: The Joinpoint Trend in U.S. Cervical Cancer Mortality with Associated Annual Percent Change (\%) Between 1975-2009, All Races, Female. 7

Table 4: The Joinpoint Trend in U.S. Prostate Cancer Mortality with Associated Annual Percent Change (\%) Between 1975-2009, All Races, Male

Table 5: Comparison of Age-Adjusted Mortality Rates per 100,000 between 2005-2009 9

Table 6: List of Kentucky Counties in Area Development Districts in Study Area 20

Table 7: Percent Change in Mortality for Selected Area Development Districts. 21

Table 8: Presence of Southeastern Kentucky Health Department Services for Prostate and Cervical Cancer Screenings, 2013, Based on Study Interviews

Table 9: Kentucky Counties with Increases in Cervical Cancer Mortality, 31

Table 10: ANOVA of Percent Change in Mortality between Health Departments with No Services (N/N), No Services but Addressed in Other Ways $(\mathrm{N} / \mathrm{Y})$, and Provided Services $(\mathrm{Y} / \mathrm{N})$... 32

Table 11: ANOVA of Percent Change in Incidence between Health Departments with No Services (N/N), No Services but Addressed in Other Ways (N/Y), and Provided Services ( $\mathrm{Y} / \mathrm{N})$ 32

Table 12: Moran's Index Values for LISA Results 33

Table 13: Percent Change in Incidence for Selected Area Development Districts 38 


\section{LIST OF FIGURES}

Figure 1: KCR Generated Map of Cervical Cancer Mortality by County, 2005-2009................. 13

Figure 2: KCR Generated Map of Prostate Cancer Mortality by County, 2005-2009 .................. 13

Figure 3: KCR Generated Map of Female Breast Cancer Mortality by County, 2005-2009 ....... 14

Figure 4: KCR Generated Map of Colorectal Cancer Mortality by County, 2005-2009 .............. 14

Figure 5: ArcGIS Mapping of Percent Change in Incidence Rates for Kentucky Cancers,

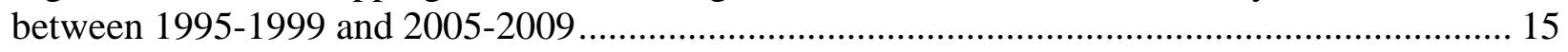

Figure 6: ArcGIS Mapping of Percent Change in Mortality Rates for Kentucky Cancers, between 1995-1999 and 2005-2009......................................................................................... 17

Figure 7: Kentucky Council of Area Development Districts in Study Area ................................. 20

Figure 8: LISA Map of Cervical Cancer Percent Change in Incidence Rate ............................... 34

Figure 9: LISA Map of Cervical Cancer Percent Change in Mortality Rate................................. 35

Figure 10: LISA Map of Prostate Cancer Percent Change in Incidence Rate ............................... 36

Figure 11: LISA Map of Prostate Cancer Percent Change in Mortality Rate ................................ 37 


\section{INTRODUCTION}

High poverty and unemployment rates, lack of health insurance, low median family income, and low population density have all been shown to correlate with high cancer mortality rates, especially in how those factors relate to education, health literacy and access in areas such as the Appalachian United States (Appalachian Regional Commission 2008). In 1999 the Kentucky Cancer Program, the Kentucky Department for Public Health, and the American Cancer Society developed an action plan with funding from the Centers for Disease Control and Prevention to tackle and address these issues. Cancer can occur in various anatomical sites, each with a unique etiology, set of risk factors, and demographic target, such as age and gender. Prevention of each type of cancer must be approached in such a way that addresses those differences. For example, cervical and prostate cancers both affect the reproductive system but clearly involve different genders, causation, and recommended screening methods. Goal six of the CDC’s action plan specifically aims to reduce cervical cancer mortality in Kentucky women through early detection and increased screening. Goal eight addresses the informed decisions of Kentucky men regarding the risks and benefits of prostate cancer screening (KCC 2012).

Nationally, both cancers have high survival rates when detected in their early stages. This supports the assertion that early detection is a crucial component of efforts to decrease mortality rates (NIH 2012). For cervical cancer, pap smears have proven to be an effective and safe screening method. With the discovery of its infectious causation, cervical cancer prevention strategies have developed even further with the recent creation and marketing of the Human Papilloma Virus (HPV) vaccine. Screening methods for prostate cancer have also been developed, including the prostate-specific antigen (PSA) test. However, the true causation of prostate cancer is still unknown and, in recent years, the PSA test has come under scrutiny. This 
reality results in differences in cancer prevention campaign strategies and limitations in the amount of funding allocated for such campaigns.

According to the Kentucky Cancer Registry, cervical and prostate cancer mortality rates have decreased significantly in southeastern Kentucky over the past twenty years (KCR 2012). Cervical cancer reduction in southeastern Kentucky has been a well-documented phenomenon with many preventative strategies implemented by local health departments. How has prostate cancer been addressed at the population-level in southeastern Kentucky, if at all, and how does it differ from the way cervical cancer has been addressed? Does prostate cancer require a different form of intervention than cervical cancer? How might population-level strategies be improved to further reduce both cancers in the region? This study examines the screening and prevention approaches of cervical and prostate cancer from the perspective of local public health departments in southeastern Kentucky through the integration of geospatial and qualitative methods. The aim of the study is to compare the way the two cancers are handled at the population level in order to identify potential reasons for the decline in age-adjusted mortality rates. 


\section{SIGNIFICANCE OF RESEARCH}

\section{Rationale and Justification}

According to the American Cancer Society, prostate cancer is the second-leading cause of cancer mortality in U.S. men, accounting for $9.7 \%$ of all cancer deaths. In contrast, cervical cancer accounts for 1.5\% of all cancer deaths of U.S. women (American Cancer Society 2013). Both are worth examining and researching in order to further reduce the effects of cancer on the U.S. population. Historically, higher overall cancer mortality has been associated with the state of Kentucky and, even more so, the Appalachian counties (Appalachian Regional Commission 2008). However, whereas Kentucky has one of the highest cervical cancer death rates in the nation, along with several other states in the southeastern United States, the prostate cancer death rate is only slightly above average (CDC 2012). As a result, certain cancers, such as lung, breast, cervical, and colorectal have received more attention from publically funded health agencies and initiatives than cancers of other sites (KCC 2012). As scientists work to discover the complex etiologies of various site-specific cancers, cancer screening and prevention programs and services are designed and offered based on the scientific evidence and funding support available. It is very important to analyze cancer trends and potential reasons for success of preventive measures so methods can be improved and shared in order to minimize excess death.

\section{Personal Motives}

In an effort to better understand how to evaluate changes in disease trends and how successes in screening and prevention outreach may relate to those changes, a comparison of prostate and cervical cancer prevention strategies was proposed for this project. Because Appalachian Kentucky is a region of great personal interest, the initial exploratory spatial data analysis (ESDA) was designed to identify any visible and interesting trends in that area. 


\section{BACKGROUND INFORMATION}

The Importance and Impact of Cancer Screening and Prevention

According to the National Cancer Institute, cancer screening refers to medical tests designed to find cancer at an early stage prior to any symptoms. This is critical because for most cancers, noticeable symptoms are an indication that the cancer has grown and spread. At later stages, cancers are often much more difficult to treat and cure. Screenings can involve physical exams and history taking, laboratory tests, imaging procedures, and even genetic tests in search of a gene mutation. Screening methods can be subject to potential harms and false results and do not necessarily guarantee increased longevity. Depending on the type and site of the cancer in question, the success of screening can vary (NCI 2012). Screenings are not used to diagnose cancer, but they can provide information regarding the next steps towards a diagnosis. An abnormal screening result can lead to the decision to perform a more invasive biopsy. The U.S. Preventative Services Task Force (USPSTF) has the responsibility of creating centralized recommendations about the frequency and target demographics of various screening methods (USPSTF 2012). These recommendations often directly influence health policy, fund allocation, and public medical opinions.

Through the use of clinical trials and various epidemiological studies, the effectiveness and safety of cancer screenings can be determined. If a test is found to be accurate and confident, then it becomes a standard test, like pap smears have become for cervical cancer (NCI 2012). Signs that a screening method is of use can be determined by looking at increased early-stage diagnosis incidence rates and decreased age-adjusted mortality rates. The Surveillance, Epidemiology, and End Results (SEER) program of the National Cancer Institute aims to collect data on survival rates to see if early detection truly affects longevity. These studies try to account for misleading trends due to over-diagnosis and "lead-time bias," or the appearance of an 
increase in survival time simply because the test led to an earlier diagnosis. The SEER data regarding the cancers of interest in this study, cervical and prostate, show that the earlier stage of detection leads to a greater chance of recovery (Tables 1 and 2). Relative survival is a measure of the cancer patient survival in comparison to the general population in order to account for the effect of the cancer.

Table 1: Cervical Cancer 5-year Relative Survival by Stage at Diagnosis for 2002-2008, All Races, Female

\begin{tabular}{|c|c|}
\hline Stage at Diagnosis & 5-year Relative Survival (\%) \\
\hline Localized (confined to primary site) & 90.7 \\
\hline Regional (spread to regional lymph nodes) & 56.7 \\
\hline Distant (cancer has metastasized) & 16.2 \\
\hline
\end{tabular}

(SEER 2012)

Table 2: Prostate Cancer 5-year Relative Survival by Stage at Diagnosis for 2002-2008, All Races, Male

\begin{tabular}{|c|c|}
\hline Stage at Diagnosis & 5-year Relative Survival (\%) \\
\hline Localized (confined to primary site) & 100.0 \\
\hline Regional (spread to regional lymph nodes) & 100.0 \\
\hline Distant (cancer has metastasized) & 27.8 \\
\hline
\end{tabular}

(SEER 2012)

Relative survival is high when the cancer is diagnosed earlier at more localized sites.

Screening methods can help attain an early diagnosis. Such tests often come with a medical bill attached, so there have been many publicly-funded efforts to make these services available to those at high risk who don't have the ability to pay for such services. Another very important strategy in the fight against cancer is prevention. Cancer prevention can include counseling people to alter their diet, engage in physical activity, avoid risk behaviors such as smoking, and even obtain vaccination for cancers of infectious origin. 


\section{Cervical Cancer}

Cervical cancer occurs at the cervix uteri, which connects the uterus to the vagina. It is primarily caused by a sexually transmitted infectious agent known as the Human Papilloma Virus (HPV). Approximately 70\% of cervical cancer cases have been linked to the types 16 and 18 of the virus (Roden and Wu 2006). HPV has also been associated with other gynecological cancers of the vulva and vagina. Several exacerbating risk factors include smoking, positive HIV status, the prolonged use of birth control pills, and giving birth to multiple children. In its early stages, cervical cancer may not cause overt symptoms, but in later stages symptoms include abnormal vaginal bleeding or discharge. Screening before these symptoms occur is crucial to the prevention of cervical cancer. An abnormal test result of cancerous cells will prompt treatment. Depending on the severity, treatment may consist of chemotherapy, radiation therapy, or surgical removal of tissue (CDC 2012).

The Pap smear, the standard screening test used for the early detection of cervical cancer, is a collection of cervical cells and mucous which is sent to a laboratory to look for precancerous cells. It is often performed in conjunction with a physical pelvic exam. The same sample can also be checked for HPV to see if the patient has been infected (CDC 2012). As of March 2012, the Preventive Services Task Force recommendation for the Pap smear is "screening for cervical cancer in women ages 21 to 65 years with cytology (Pap smear) every 3 years or, for women ages 30 to 65 years who want to lengthen the screening interval, screening with a combination of cytology and human papillomavirus (HPV) testing every 5 years (USPSTF 2012).”

The discovery of the role of HPV in the etiology of cervical cancer has prompted the development and widespread distribution of the HPV vaccine. Currently, there are two vaccines available, Cervarix and Gardasil. The vaccine is administered over 6 months in 3 consecutive 
doses. The recommended age for the vaccine is 11 to 12 , in order to give the immune system time to develop a response prior to sexual activity. The vaccine is available to both boys and girls, since males can harbor the virus and spread it sexually to others. The development of the vaccine has increased the scope of the target age demographic for cervical cancer prevention and has become an important part of the strategies of public health departments.

At one time, cervical cancer was the leading cause of cancer death of women in the United States. According to the CDC databases, this has been reduced significantly in the last 40 years due to the wide spread use of the Pap smear screening method. Joinpoint analyses of cancer trends can be used to evaluate changes in mortality over a period of time by using criteria to determine when and how frequently mortality rates have changed. The results are given as ranges in calendar years and the annual percent change (APC) in the mortality rates over each period. The joinpoint trend of cervical cancer mortality from 1975 to 2009 indicates a continued decline in rates (Table 3).

Table 3: The Joinpoint Trend in U.S. Cervical Cancer Mortality with Associated Annual Percent Change (\%) between 1975-2009, All Races, Female

\begin{tabular}{|c|c|}
\hline Trend & Period \\
\hline-4.3 & $1975-1982$ \\
\hline-1.6 & $1982-1996$ \\
\hline-3.8 & $1996-2003$ \\
\hline-0.9 & $2003-2009$ \\
\hline
\end{tabular}

(SEER 2012)

\section{Prostate Cancer}

Prostate cancer occurs at the prostate, which is a reproductive gland that produces alkaline fluid for the semen. It is located below the bladder, surrounding the urethra. With age, the prostate can increase in size and often causes problems with urination in older men. Symptoms of prostate cancer are usually associated with pain or the presence of blood during 
urination or ejaculation. The primary cause of prostate cancer is still unknown, but the disease is correlated with older age, family/genetic history, and race. For men at high risk, smoking cessation, healthier diet, and increased exercise are often considered to have a protective function against developing the cancer. Prostate cancer diagnosis is confirmed via biopsy or transrectal ultrasound. Depending on the severity of the cancer, treatment can include radiation therapy, hormonal therapy, or complete surgical removal of the prostate (CDC 2012).

There are two screenings used for detecting prostate cancer. One is known as a digital rectal exam (DRE) which consists of palpation inside the rectum to feel for an enlarged prostate or any lumps or abnormalities. The second is the prostate-specific antigen (PSA) blood test which measures the amount of PSA. A high PSA level is indicative of a prostate problem, but the level can also be high due to an infection, age, race, and medications, and does not necessarily mean the patient has prostate cancer (CDC 2012). The current cancer screening recommendation for prostate cancer includes a digital rectal exam (DRE) for men over age 50. Due to high variability in PSA test results and misdiagnosis of asymptomatic prostate conditions, in May 2012 the USPSTF recommended against PSA-based screening (USPSTF 2012). In practice, the PSA test continues to be ordered by many medical practitioners for men at average risk after age 50 and for men at unusually high risk because of family history or other factors after age 40 . Before the use of this test, it is very important that the patient undergoes an informed decisionmaking process sifting through the benefits, risks, and uncertainties. False positives can cause unnecessary anxieties. Subsequent diagnostic biopsies may lead to complications (Smith 2011).

In the United States, prostate cancer is the second leading cause of cancer death in men. The PSA test received FDA approval in 1986 as a monitor for treatment response and disease recurrence, and in 1994, as a screening tool for diagnosis (RPCI 2010). The joinpoint trend of 
prostate cancer mortality from 1975 to 2009 indicates that rates began to decrease after the 19911994 time period which points to the beneficial effects of the PSA test (Table 4).

Table 4: The Joinpoint Trend in U.S. Prostate Cancer Mortality with Associated Annual Percent Change (\%) between 1975-2009, All Races, Male

\begin{tabular}{|c|c|}
\hline Trend & Period \\
\hline 0.9 & $1975-1987$ \\
\hline 3.1 & $1987-1991$ \\
\hline-0.7 & $1991-1994$ \\
\hline-3.9 & $1994-2004$ \\
\hline-3.2 & $2004-2009$ \\
\hline
\end{tabular}

(SEER 2012)

Cancer in Southeastern Kentucky

Cancer is the second-leading cause of death in the state of Kentucky, surpassed only by cardiovascular disease (KYCHFS 2010). Lung, colorectal, breast, and prostate are the four most common causes of cancer-related death in the state (KCR 2012). By comparing the age-adjusted mortality rates for cancer between the U.S., the state of Kentucky, non-Appalachian Kentucky and Appalachian Kentucky, we can draw conclusions about how the Appalachian parts of Kentucky are doing in relation to the rest of the country (Table 5). For all cancer sites and cervical cancer, there is a difference between non-Appalachian and Appalachian areas. For prostate cancer, the rate of the Appalachian region seems rather consistent with the nonAppalachian region and the rest of the country. In fact, the mortality rate is slightly higher for non-Appalachian KY.

Table 5: Comparison of Age-Adjusted Mortality Rates per 100,000 between 2005-2009

\begin{tabular}{|c|c|c|c|c|}
\hline Cancer Site & U.S. & Kentucky & Non-Appalachian KY & Appalachian KY \\
\hline All Sites & 178.7 & 208.6 & 201.8 & 224.8 \\
\hline Cervical & 2.4 & 2.9 & 2.6 & 3.5 \\
\hline Prostate & 23.6 & 24.3 & 24.3 & 24.1 \\
\hline
\end{tabular}

(SEER 2012 and KCR 2012) 
A study based in Ohio explored the differences in mortality rates between Appalachian and non-Appalachian regions for various types of cancers, including cervical and prostate. The study discovered that cervical cancer mortality rates were much higher in Appalachian counties, but mortality rates were actually lower for prostate. Of all the cancers studied, cervical cancer appeared to be most associated with disparities in healthcare access and risk behaviors. Evidence from the Youth Risk Behavior Surveillance System suggested that earlier sexual intercourse of Appalachian girls linked to the infectious causation of cervical cancer may play a role in these differences (Fischer 2008). Although we can’t directly apply these findings to the situation in the state of Kentucky, it certainly gives us something to think about with regards to the urgency of a disparity-related cancer like cervical in Appalachian counties versus prostate cancer which doesn't seem to be correlated with disparity.

\section{Barriers to Screening and Prevention}

One of the greatest barriers to cancer screening and prevention is the inability to pay for screening and subsequent treatment if needed. In 1990, the U.S. congress passed the Breast and Cervical Cancer Mortality Prevention Act which enabled the creation of the CDC's National Breast and Cervical Cancer Early Detection Program. The program’s objectives were to provide uninsured and underserved women in the United States access to breast and cervical screening services, including mammograms, Pap smears, HPV tests, diagnostic testing for abnormal results, and treatment referrals. In 2000, Congress passed the Breast and Cervical Cancer Prevention and Treatment Act in order to further extend funding for treatment, too. Under this new legislation, women could participate in the Breast and Cervical Cancer Treatment Program (BCCTP) and obtain access to a Medicaid medical card to pay for services. These programs have 
eligibility requirements; for example, the patient must be a certain age and must be at or below 250\% of the federal poverty level (CDC 2012).

Prostate cancer has not received the legislative support that cervical cancer has, and health workers in various communities still confront many challenges. According to some findings, men often have greater difficulty participating in preventive services than women do. A study on the health perspectives of Appalachian women showed that women often play the roles of "gatekeepers" to the health of their families. They are much more likely to communicate with doctors about their own health concerns and are more likely to participate in annual preventative exams (Schoenberg et al. 2008). Men, on the other hand, are more likely to forgo things like cancer screenings. One interesting qualitative study looked at the barriers to and sources of influence for prostate cancer screening among rural men. The study found that most men in the study feared that prostate screening would be too embarrassing, painful, and long (Oliver et al. 2011).

Despite these known barriers to cancer screening and prevention, southeastern Kentucky counties seem to have found a way to overcome some of these challenges, as indicated by the decreases in mortality rates for both prostate and cervical cancers. This study seeks to examine what has been done during the past twenty years and what is currently being done to address these cancers from the perspectives of county and district-level public health departments. 


\section{METHODOLOGY}

Type of Study

This study used both geospatial and qualitative methods to examine changes in cervical and prostate cancer mortality in 21 counties in southeastern Kentucky between two time periods 1995-1999 and 2005-2009. The result is a presentation of geospatial results and discussion of the qualitative themes and patterns that resonate throughout the Big Sandy, Cumberland Valley, and Kentucky River districts regarding potential differences in the implementation of cancer screening and prevention programs for cervical and prostate cancers. Studies with cancer mortality have limitations based on the fact that cancer often has long latency periods and has multi-factorial causations and risk factors. The study did not aim to specifically associate a particular program or strategy with decrease in mortality rates, only to search and identify potential explanations for why cervical and prostate cancer efforts seem to have been so successful in a region that has historically suffered from healthcare disparities.

\section{Exploratory Spatial Data Analysis (ESDA)}

In order to get a general idea of cancer mortality trends in the region of interest, Appalachian Kentucky, exploratory spatial data analysis (ESDA) was performed. Using the online Kentucky Cancer Registry (KCR 2012) interactive mapping tool, county-level incidence and mortality rates for cancers of the breast, cervix uteri, prostate, and colon were recorded (Figures 1, 2, 3, and 4). For each cancer, rates were mapped for the time periods of 1995-1999 and 2005-2009, respectively. All four cancers listed above were chosen for initial analysis because the state of Kentucky is actively working to address each according to the CDC's action plan (KCC 2012) and because there are set recommendations for their screening methods. 
Figure 1: KCR Generated Map of Cervical Cancer Mortality by County, 2005-2009

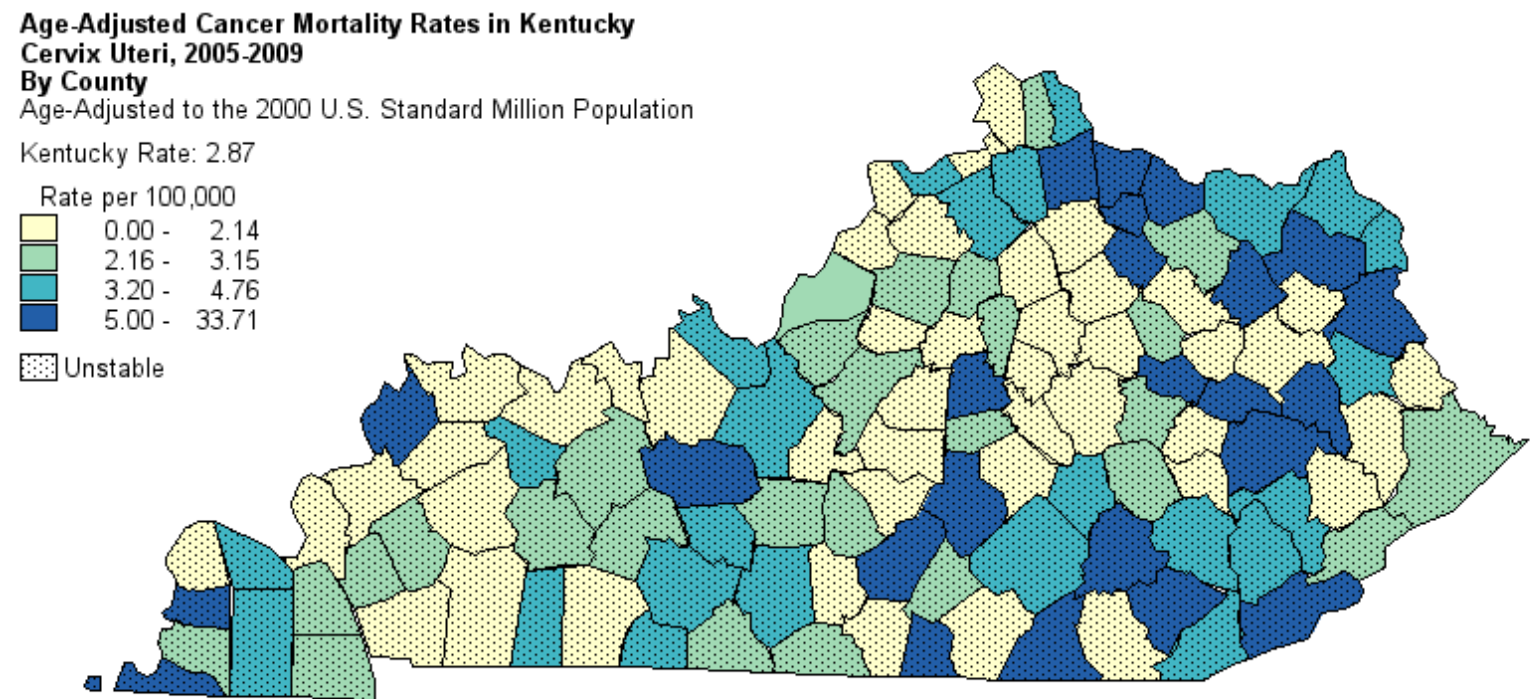

Data accessed February 24, 2013

Based on data released October 10, 2012

Copyright (C) 2013 Kentucky Cancer Registry

Figure 2: KCR Generated Map of Prostate Cancer Mortality by County, 2005-2009

Age-Adjusted Cancer Mortality Rates in Kentucky Prostate, 2005-2009

By County

Age-Adjusted to the 2000 U.S. Standard Million Population

Kentucky Rate: 24.27

Rate per 100,000

$0.00-18.39$

$18.62-23.18$

$23.37-29.24$

$29.55-75.65$

Unstable

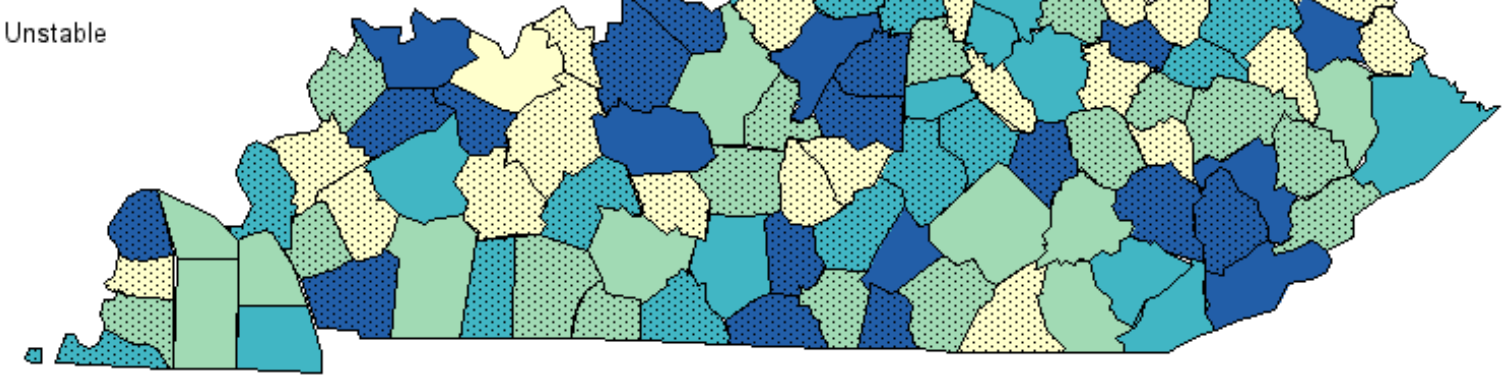

Data accessed February 24, 2013

Based on data released October 10, 2012.

Copyright (C) 2013 Kentucky Cancer Registry 
Figure 3: KCR Generated Map of Female Breast Cancer Mortality by County, 2005-2009

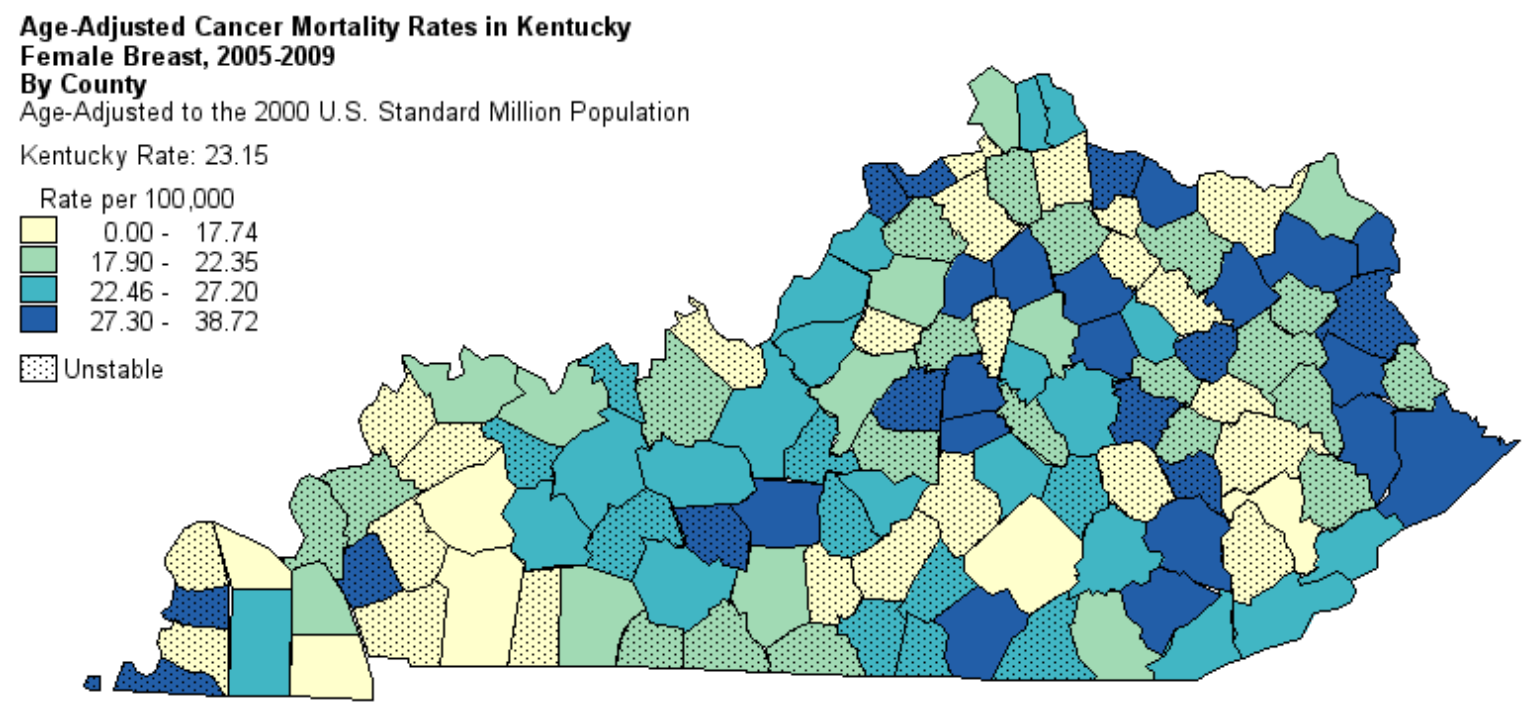

Data accessed February $24,2013$.
Based on data released October 10, 2012.

Copyright (C) 2013 Kentucky Cancer Registry

Figure 4: KCR Generated Map of Colorectal Cancer Mortality by County, 2005-2009

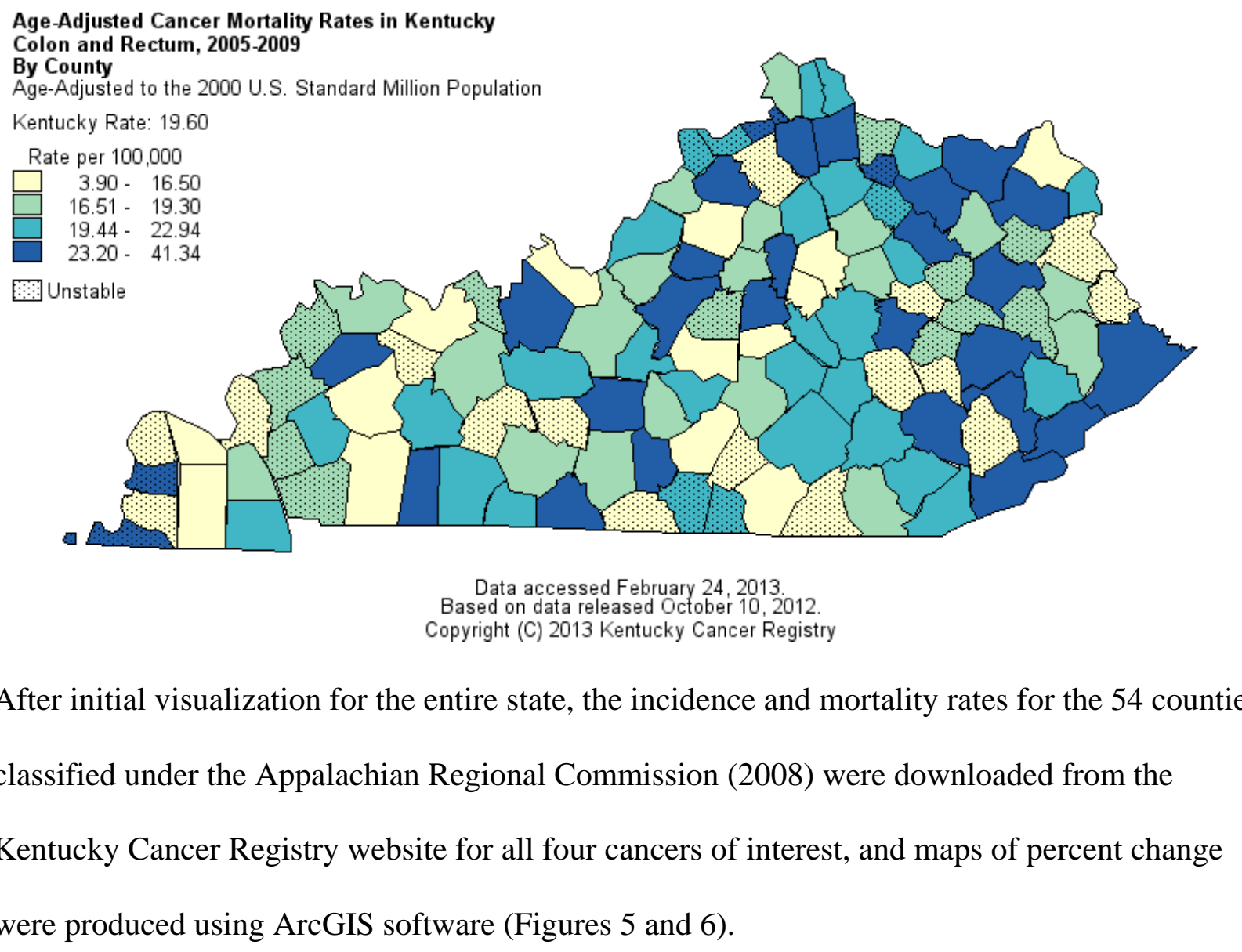


Figure 5: ArcGIS Mapping of Percent Change in Incidence Rates for Kentucky Cancers, between 1995-1999 and 2005-2009

a) Breast

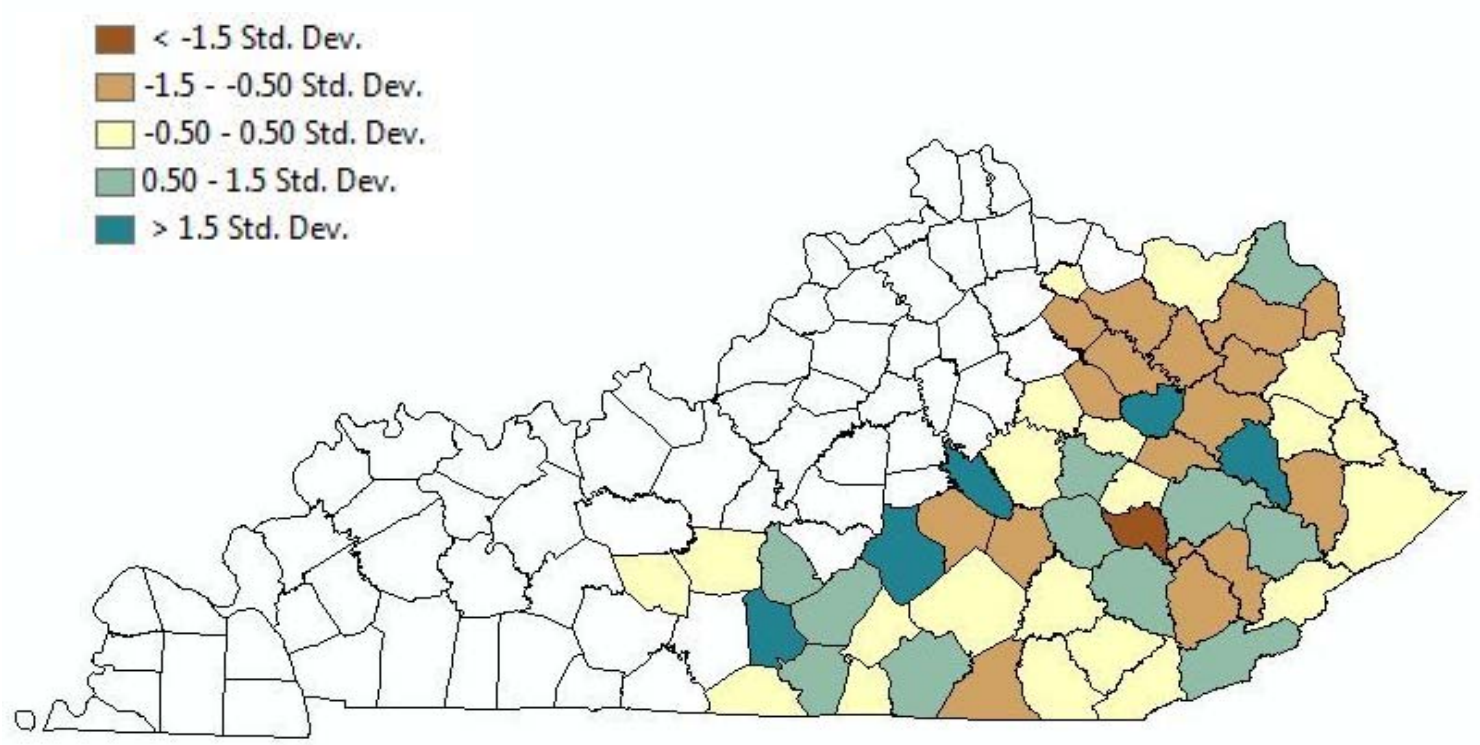

b) Cervical

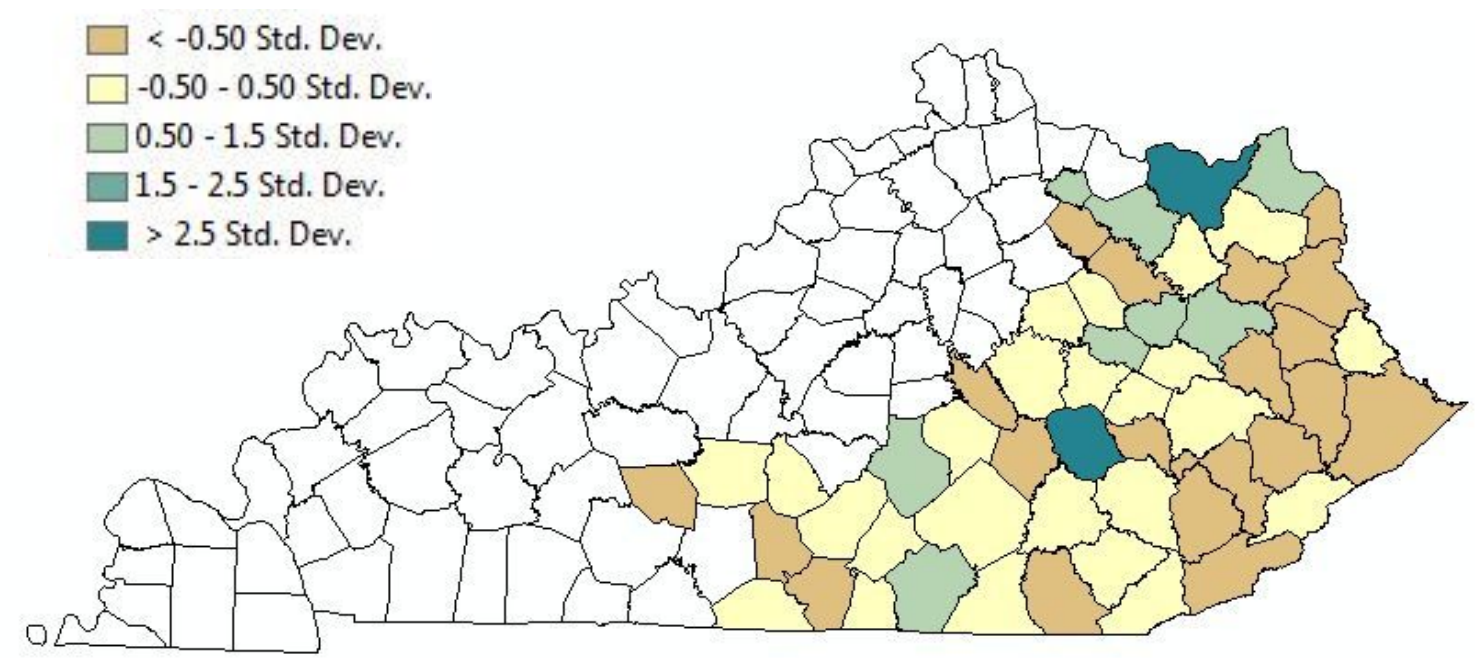


c) Colon - Female

$<-1.5$ Std. Dev.

$-1.5--0.50$ Std. Dev.

$-0.50-0.50$ Std. Dev.

$0.50-1.5$ Std. Dev.

1.5 - 2.5 Std. Dev.

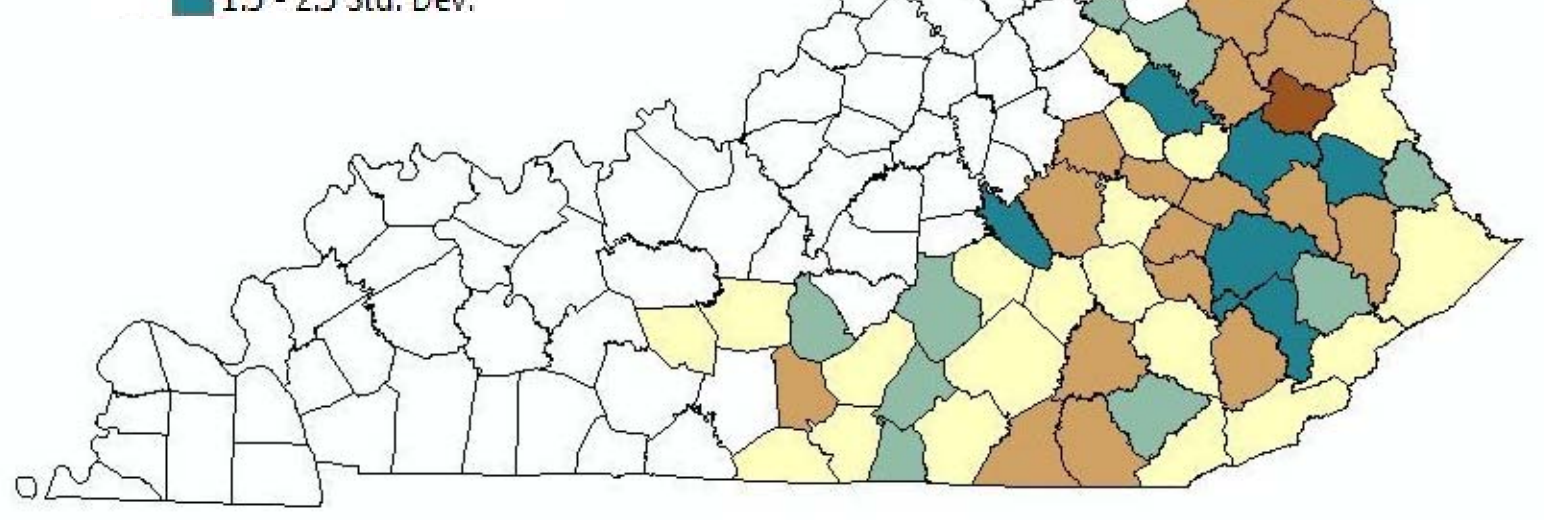

d) Colon - Male

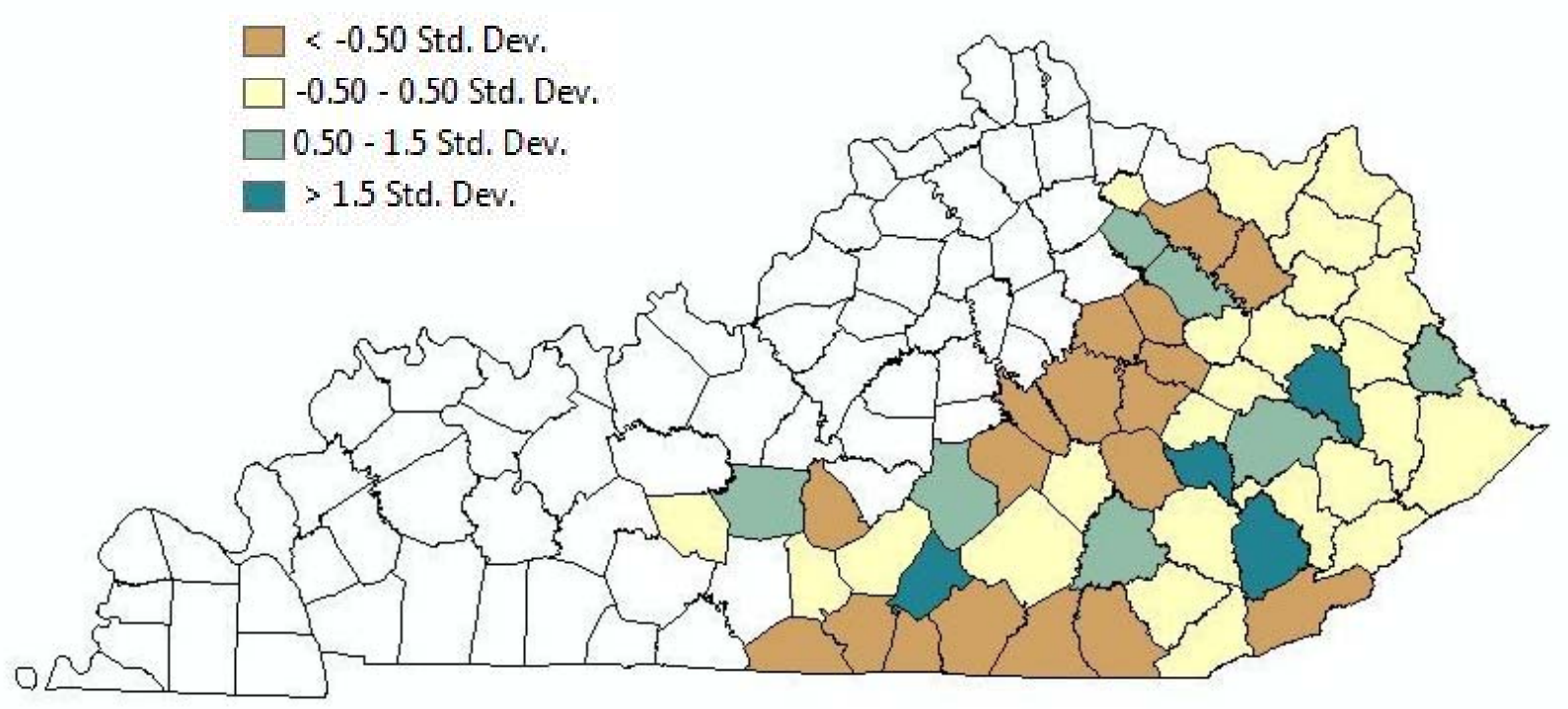




\section{e) Prostate}

$<-1.5$ Std. Dev.

$-1.5--0.50$ Std. Dev. $-0.50-0.50$ Std. Dev. $0.50-1.5$ Std. Dev. $1.5-2.5$ Std. Dev. $>2.5$ Std. Dev.

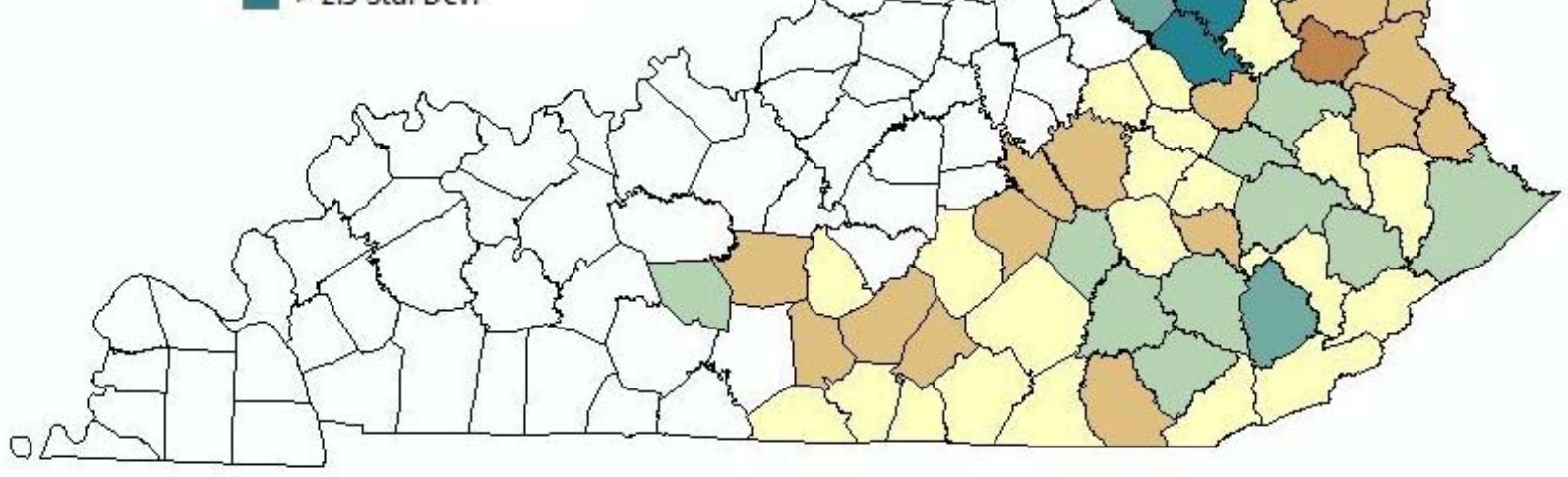

Figure 6: ArcGIS Mapping of Percent Change in Mortality Rates for Kentucky Cancers, between 1995-1999 and 2005-2009

\section{a) Breast}

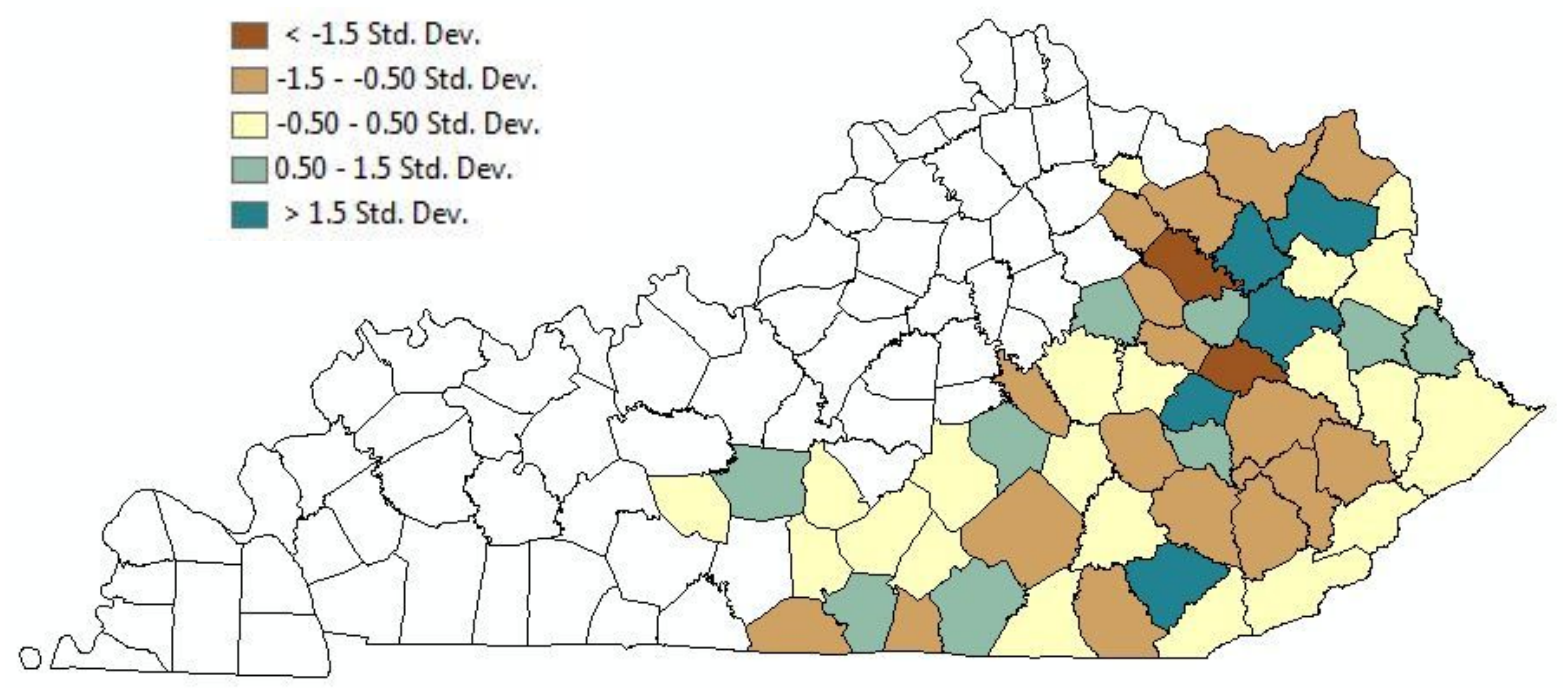




\section{b) Cervical}

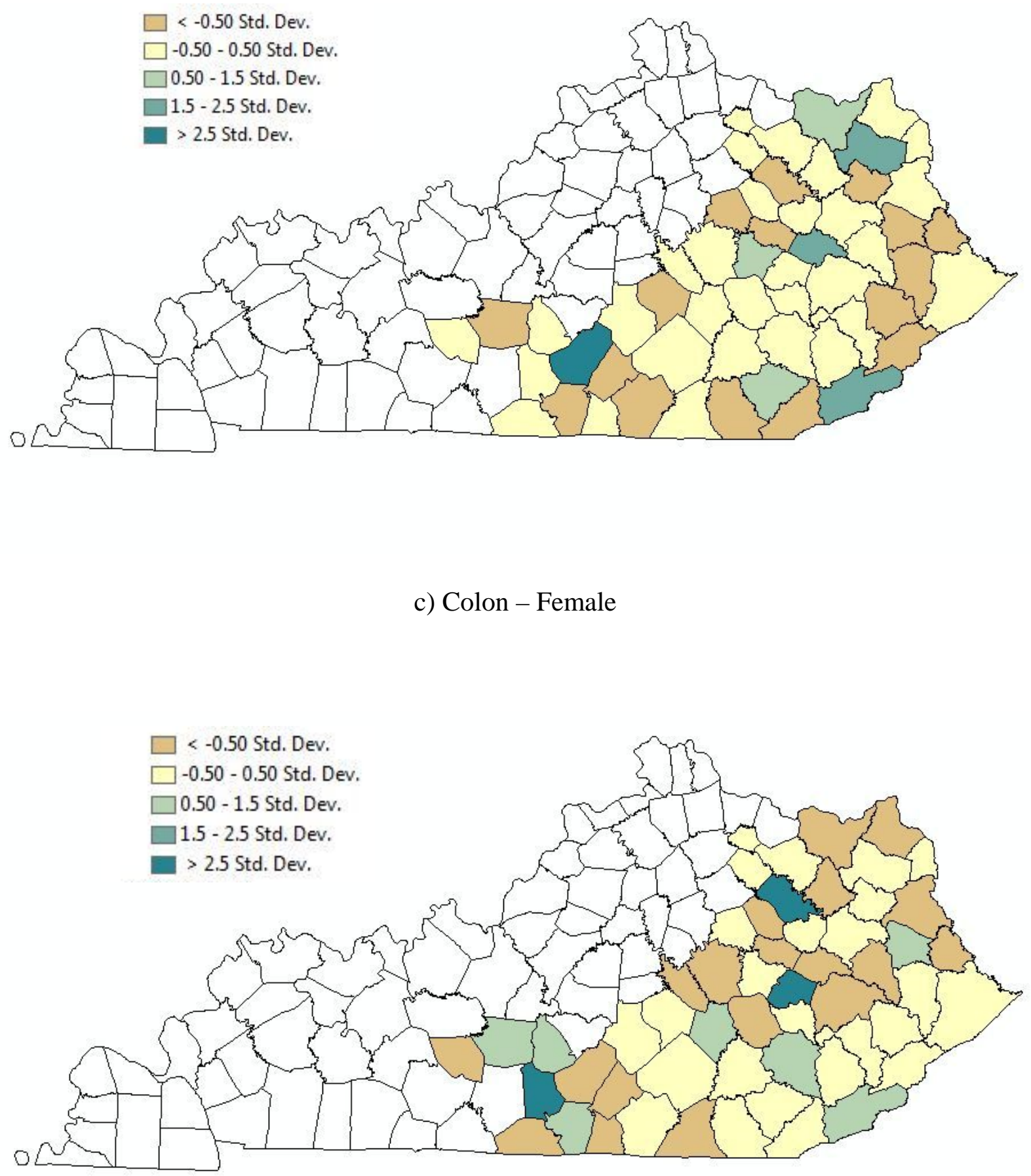




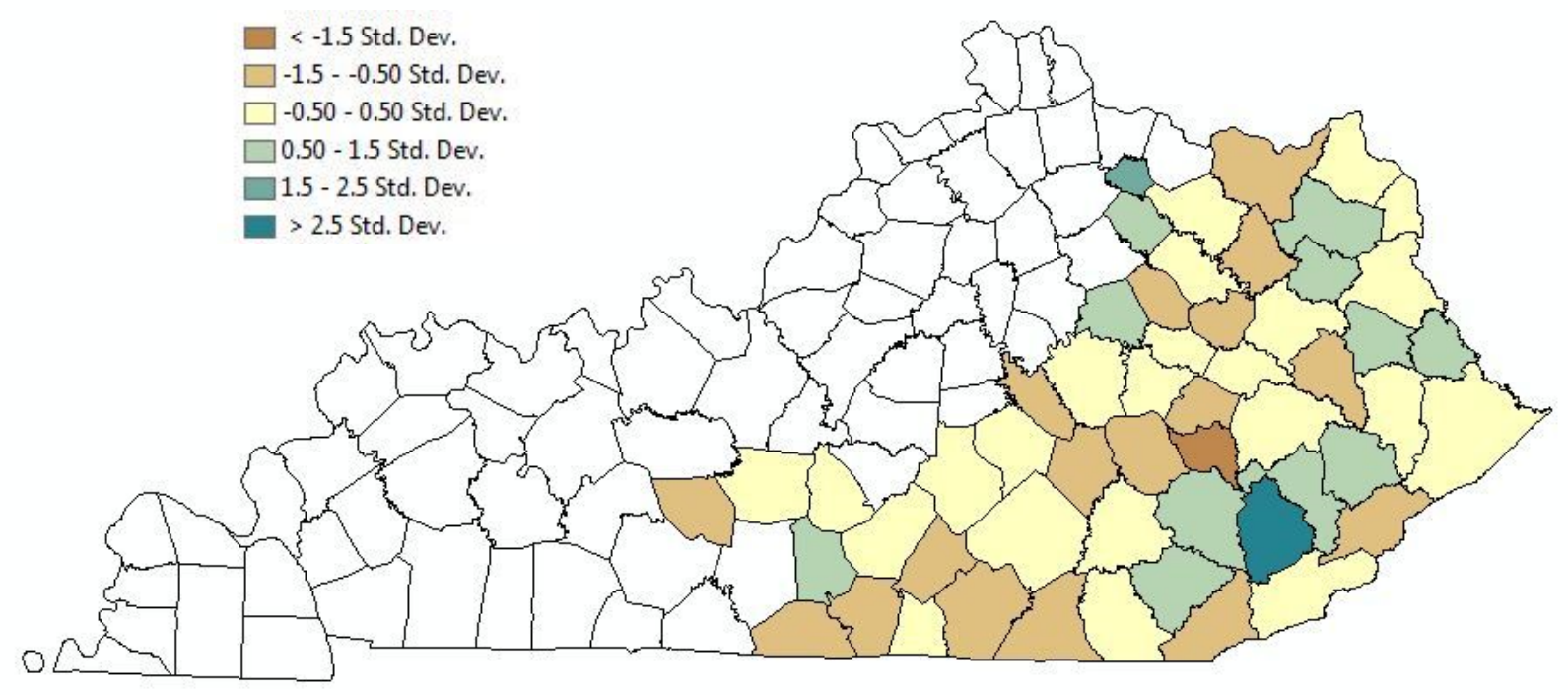

e) Prostate

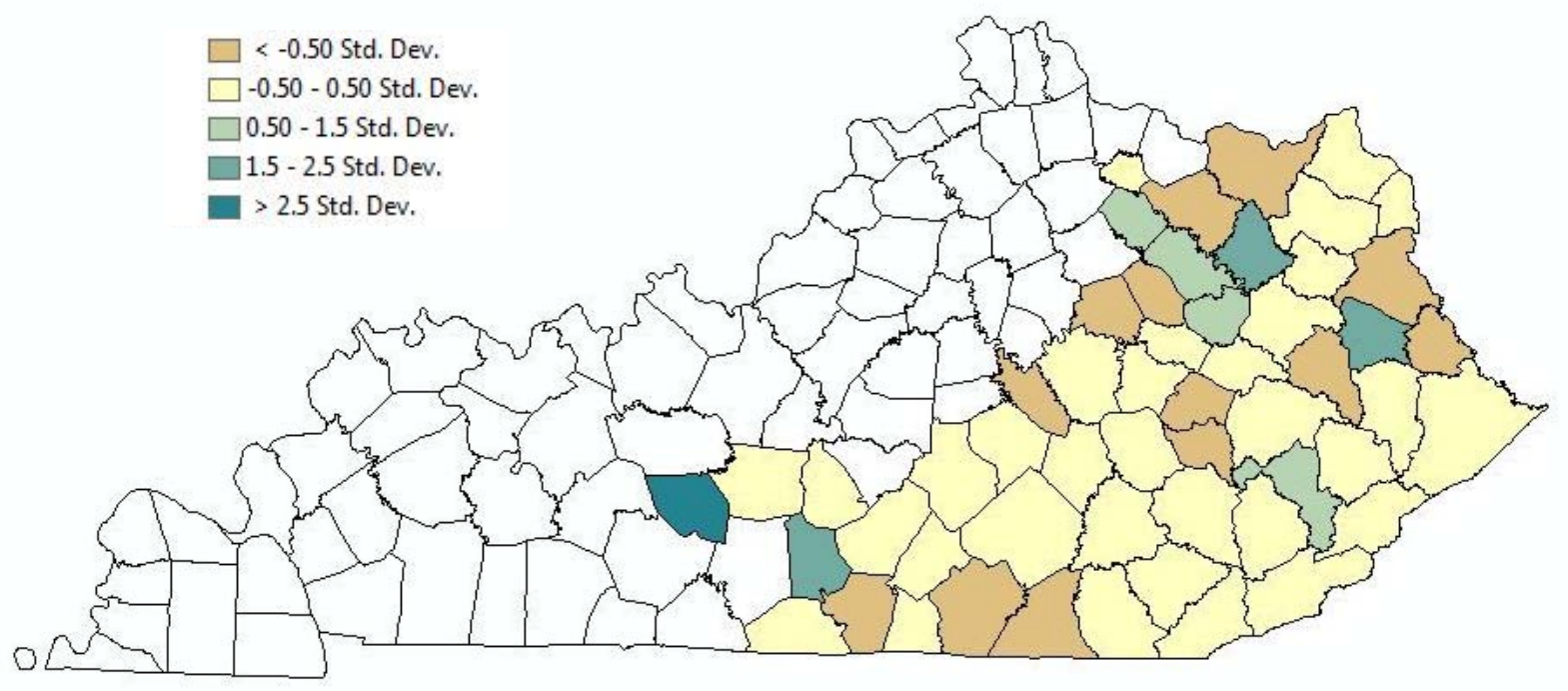


By looking at the percent change between 1995-1999 and 2005-2009, the cancers with the highest regional increase or decrease in mortality and incidence could be determined. Through the ESDA, cancer mortality trends were visualized, which helped in the selection of which counties and which cancers to explore. Prostate and cervical cancer appeared to have the clearest mortality decrease and were chosen for further analysis.

\section{Location of Study}

Based on the information gathered during the ESDA, 21 Appalachian Kentucky counties that comprise the area development districts (ADDs) of Big Sandy, Kentucky River and Cumberland Valley were selected (Table 6). These are shown in Figure 7. ADDs are regions of the state that are headed by councils who oversee various planning issues and services.

Table 6: List of Kentucky Counties in Area Development Districts in Study Area

\begin{tabular}{|c|c|c|}
\hline Big Sandy & Kentucky River & Cumberland Valley \\
\hline $\begin{array}{c}\text { Floyd, Johnson, Magoffin, } \\
\text { Martin, Pike }\end{array}$ & Breathitt, Knott, Lee, Leslie, \\
Letcher, Owsley, Perry, Wolf & $\begin{array}{c}\text { Bell, Clay, Harlan, Jackson, } \\
\text { Knox, Laurel, Rockcastle, } \\
\text { Whitely }\end{array}$ \\
\hline
\end{tabular}

Figure 7: Kentucky Council of Area Development Districts in Study Area

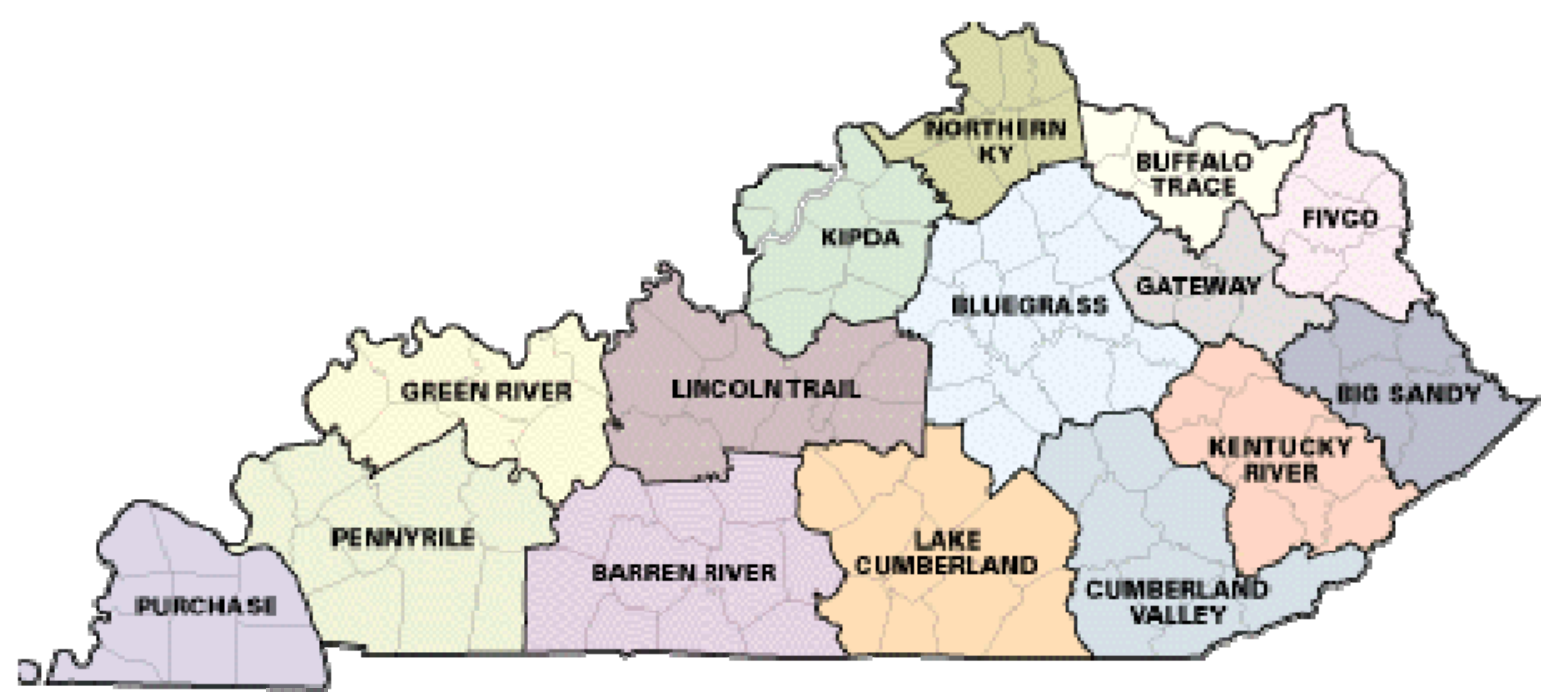

(KCADD 2009) 
This region showed improved cervical and prostate cancer outcomes over the two time periods, 1995-1999 and 2005-2009. Table 7 shows percent changes in mortality rates between the two time intervals for the three area development districts (Table 7). The decline in cervical and prostate cancer mortality was found to be consistent across all three ADDs in a preliminary data analysis of mortality rates published by the KCR (2012).

Table 7: Percent Change in Mortality for Selected Area Development Districts

\begin{tabular}{|c|c|c|}
\hline \multicolumn{2}{|c|}{ Percent Change in Age-Adjusted Mortality Rates in Appalachian Kentucky } \\
& (1995 -1999 to 2005 -2009) & Prostate \\
\hline Area Development District & Cervical Cancer & $-15.28 \%$ \\
\hline Big Sandy & $-66.90 \%$ & $-29.67 \%$ \\
\hline Cumberland Valley & $-28.55 \%$ & $-27.47 \%$ \\
\hline Kentucky River & $-21.36 \%$ & \\
\hline
\end{tabular}

(KCR 2012)

\section{Data-Gathering Procedures}

Cancer mortality statistics and online interactive mapping applications provided by the Kentucky Cancer Registry (KCR 2012) were used to geographically confirm that the three-ADD study area has seen a decline in cervical and prostate cancer mortality from 1995 to 2009. Qualitative data collection in the form of semi-structured interviews served as a means of investigating the possible reasons for the cancer mortality trends of cervical and prostate cancer in the study area. The interviews were conducted with directors and representatives of Kentucky public health departments. The questions were mostly open-ended and incorporated topics such as which cancer screening and prevention strategies were in place, if and how they made an impact, which links exist between the program and the observed impact, and the perceived barriers to decreasing cancer mortality rates (see Appendix I: Interview Questions). There are 21 counties located in the ADDs of the Big Sandy, Cumberland Valley, and Kentucky River, but some counties have merged into district health departments. The Cumberland Valley District 
incorporates the counties of Clay, Harlan, Jackson, and Rockcastle. The Kentucky River District Health Department incorporates the counties of Knott, Lee, Leslie, Letcher, Owsley, Perry, and Wolf. The remaining 10 counties are overseen by independent county health departments. Interviews were conducted with all 12 departments in the region of interest.

\section{Data-Analysis Procedures}

The interview questions were written in a semi-structured format in order to allow the interviewee to expand on various topics of concern. The responses to all questions were analyzed and categorized into various themes. Topics that were addressed by one interviewee were not necessarily addressed by others. The interview structure allowed for this type of variation in order to gather the most information possible regarding the individual communities and how the health department representative viewed the issues within his or her own community. The extent that prostate cancer was addressed was measured by determining whether or not a health department provided prostate cancer screening services and whether or not they could comment on services that were offered in the community by other entities. This was juxtaposed against the extent to which cervical cancer screening services were offered by the same health department.

An iterative process was utilized. Once qualitative data were collected and analyzed, the research returned to geospatial methods in order to determine how interview responses corresponded to individual-county and district mortality rates. Statistical methods included analysis of variance (ANOVA) of incidence and mortality rates of prostate cancer between counties that offered no prostate screening services, counties that did not offer services through the department but noted effective outside services, and counties with departments that did offer prostate screening services. The objective was to see if there was more variation within these groupings or between groupings to see if the presence of services correlated with greater 
decreases in mortality rates. Next, a geospatial method known as the local index of spatial autocorrelation (LISA) was used to evaluate the possible existence of spatial clusters of cancer rates in the region of study, specifically whether or not certain counties had higher or lower rates than would normally be expected due to chance. For the LISA method, the free software, GeoDa (GeoDa 2013) was used. In addition, attention was returned to incidence rate data for both prostate and cervical cancer to see how information extracted from the qualitative interviews might explain the trends. 


\section{RESULTS}

The interviews produced a variety of themes and information in regards to how cervical and prostate cancers are dealt with in southeastern Kentucky communities by the public health departments. It was clear that all public health departments provided standard services for cervical cancer screening and prevention. When asked about prostate cancer screening and prevention, very few interviewees provided knowledge of services offered directly by the department. Some interviewees mentioned other prostate cancer screening efforts outside of the public health department that seem to have been effective in recent years (Table 8). The information extracted from the interviews showed that prostate cancer screening and prevention was not a common initiative of county and district level health departments.

Table 8: Presence of Southeastern Kentucky Health Department Services for Prostate and Cervical Cancer Screenings, 2013, Based on Study Interviews

\begin{tabular}{|l|c|c|c|}
\hline Health Department & $\begin{array}{l}\text { Cervical Cancer } \\
\text { Services Provided by } \\
\text { Department? }\end{array}$ & $\begin{array}{l}\text { Prostate Cancer } \\
\text { Services Provided by } \\
\text { Department? }\end{array}$ & $\begin{array}{l}\text { Mentioned Prostate } \\
\text { Cancer Services } \\
\text { Provided by Others? }\end{array}$ \\
\hline Bell County & Yes & No & No \\
\hline Breathitt County & Yes & No & No \\
\hline $\begin{array}{l}\text { Cumberland Valley } \\
\text { District (Clay, } \\
\text { Harlan, Jackson, } \\
\text { Rockcastle) }\end{array}$ & Yes & & \\
\hline Floyd County & & Yes & No \\
\hline Johnson & No & No \\
\hline $\begin{array}{l}\text { Kentucky River } \\
\text { District (Knott, Lee, } \\
\text { Leslie, Letcher, } \\
\text { Owsley, Perry, Wolf) }\end{array}$ & Yes & No & Yes \\
\hline Knox & Yes & & No \\
\hline Laurel & & & Yes \\
\hline Magoffin & & No & No \\
\hline Martin & Yes & No & No \\
\hline Pike & Yes & No & No \\
\hline Whitely & Yes & No & Yes \\
\hline
\end{tabular}




\section{Cervical Cancer Services}

All public health departments confirmed that there were strong programs in place for cervical cancer screening and prevention. One of the most important transitions over the past two decades has been the extension of funding from just screening to diagnostic treatment. The Whitely County Health Department stated that before this transition, women would take part in the free screenings, but if cancerous cells were discovered, they were expected to seek out treatment on their own even if they were without insurance (personal communication, Gail Timperio, Whitely County Health Department, 2/11/2013). Ten out of the 12 health departments mentioned the success of the BCCTP funding since the year 2000, which has enabled uninsured or underinsured women to have access to a Kentucky Medicaid medical card for treatment of breast and cervical cancers. The Cancer Program Director of the Breathitt County Health Department expressed frustration with the limitations on how funds are spent in this program. The funding is only for cervical and breast cancers, and if a woman is diagnosed with vaginal cancer and not cervical cancer, that medical card is no longer available to her (personal communication, Penny Mauk, Breathitt County Health Department, 2/11/2013). Nonetheless, this extension of funding was viewed as one of the major improvements in the region for cervical cancer.

Another trend that has been taking place is an increase in outreach funding and other community partnerships for southeastern Kentucky women. The Kentucky River District Health Department has been able to receive additional funding from the state for social-based activities like "Ladies Day” where women come for free health information and services and, in return for attending, are given gift cards for local businesses (personal communication, Sharon Dunaway, Kentucky River District Health Department, 2/4/2013). In Johnson County, a partnership with 
the University of Kentucky Extension Office was established in recent years. The health department has been invited to participate in the "Homemakers Program" meetings by providing information sessions and other women's health promotion activities (personal communication, Teresa Lawson, Johnson County Health Department, 2/13/2013). Other counties, such as Magoffin, have found it useful to use newspapers and other forms of media to publish information about programs and free services (personal communication, Marlene Robertson, Magoffin County Health Department, 2/11/2013).

\section{Challenges to Cervical Cancer Screening and Prevention}

Six out of 12 interviewees listed transportation to services as a major barrier for women participating in cervical cancer screening services, including the Kentucky River District and the independent counties of Martin, Magoffin, Laurel, Johnson, and Knox. To address this challenge, the Kentucky River District seeks to encourage the use of the Human Service Transportation Delivery Program. If patients meet certain criteria, they are offered free transportation to get to health services (personal communication, Sharon Dunaway, Kentucky River District Health Department, 2/4/2013).

Nine out of 12 interviewees still said that one of the greatest challenges was getting women to come in for the services, even with all of the programs available for transportation and helping with the cost of the tests. Representatives of Floyd and Pike County specified that in their communities, women may come in for the screening, but fail to return for the follow-up (personal communication, Thelma Lafferty, Floyd County Health Department, 2/11/2013;

personal communication, Stephanie Whitely, Pike County Health Department, 2/11/2013). In the Cumberland Valley District, subsidization of services is based on income qualifications. The interviewee expressed the concern that because of this detail, they can't really advertise the 
cervical cancer services as "free," and this tends to deter many women because they are afraid it will still cost them something (personal communication, Kathy Smith, Cumberland Valley District Health Department, 2/25/2013).

The health department interviewees of Breathitt, Martin, and Johnson Counties all showed deep concern about how the recent change in the USPSTF recommendation for cervical cancer screening is affecting their programs. The Cancer Program director of Breathitt County specifically exhibited great frustration with changes in policy. "We worked so hard to convince these women how important annual Pap smears were. Now we have to tell them it is only necessary once every three years? They start to lose faith in the information we give them. They become confused (personal communication, Penny Mauk, Breathitt County Health Department, 2/11/2013).” In Johnson County, when women came in for annual Pap smears, they had the convenience of synchronizing their breast exams and other important screenings. Now that Pap smears are only recommended once every three years, they assume the other exams can wait, too. “They won’t come in now just for breast (personal communication, Teresa Lawson, Johnson County Health Department, 2/13/2013).” The Program Manager of Martin County indicated she is curious to see if the policy change will affect mortality statistics several years down the road (personal communication, Penny Dye, Martin County Health Department, 2/11/2013).

\section{Prostate Cancer Services}

All public health department interviewees stated that prostate cancer screening and prevention was not a major focus for them. Only two out of the 12 health departments interviewed actually provided prostate cancer screening services. Floyd County Health Department offers a “Men’s Health Day” once a year, which falls around Father's Day and includes free PSA testing (personal communication, Thelma Lafferty, Floyd County Health 
Department, 2/11/2013). In Pike County, the department did receive federal funding to have an evening Male Clinic with a doctor who provided services for sexually-transmitted diseases (STDs) and PSA tests. However that funding was recently cut despite good participation (personal communication, Stephanie Whitely, Pike County Health Department, 2/11/2013). A few interviewees mentioned successful prostate cancer screening services that were offered by the private sector. In the Kentucky River District, it has been observed that some private insurance companies associated with employers such as Wayne Supply have been instituting "well visits" on-site. Medical providers come to the workplace, provide health information, perform physicals, and offer PSA tests. In this environment, the men take part in health promotion and prevention with the moral support of their own peers and co-workers and, most importantly, do not have to miss work to go to the doctor for these services (personal communication, Sharon Dunaway, Kentucky River District Health Department, 2/4/2013). Whitely County and Laurel County Health Department representatives both claimed that one of the major successes in prostate cancer mortality decrease in their communities was due to the fact that more healthcare providers have come into the area and have been spreading awareness about the benefits of screening and have, as a result, ordered more PSA tests (personal communication, Gail Timperio, Whitely County Health Department, 2/11/2013; personal communication, Deborah Hackert, Laurel County Health Department, 2/11/2013). There are no hard data in this particular study to support this claim, however, it would be interesting in a future study to gather information to confirm this speculation.

\section{Challenges to Prostate Cancer Screening and Prevention}

With the exception of Floyd and Pike Counties which explicitly provided PSA testing services, most public health departments claimed to only see men rarely and for services like 
STD testing, flu shots, other vaccinations, home health, diabetic counseling, and work-related adult prevention physicals. In the Kentucky River District, when men are in for these types of routine services, the nurses try to use the opportunity to provide men in the target demographic with information about prostate cancer so that they will consider asking their doctor about pursuing screening (personal communication, Sharon Dunaway, Kentucky River District Health Department, 2/4/2013). All interviewees agreed that the reality is that funding is not available for prostate cancer-specific programs. "We can only do what we get funding for. I personally think that hepatitis is a huge problem is this community, but we can't do much for it at the moment (personal communication, Teresa Lawson, Johnson County Health Department, 2/13/2013).” However, not all interviewees even saw prostate cancer as a pressing problem in their communities. For example, the clinic representative from Magoffin County Health Department even asserted that prostate cancer wasn't a true problem in their community and that the department should be focusing more on the health issues of women instead, especially cervical and breast screenings (personal communication, Marlene Robertson, Magoffin County Health Department, 2/11/2013). Very few interviewees chose to elaborate on the issue of prostate cancer, primarily because the public health departments simply do not provide services for it. The Whitely County Health Department interviewee felt that mixed messages regarding the need for and reliability of the PSA test was a major barrier for men across the region. The men begin to question whether or not the screening is truly necessary and become confused about the information they hear from others and on the news regarding changes in USPSTF recommendations (personal communication, Gail Timperio, Whitely County Health Department, 2/11/2013). All departments expressed that from their observations, men in general do not seek 
out preventative services or health providers as often as women and have a very stubborn attitude about their health.

\section{Gender Differences in General Cancer Screening Services}

All interviewees suggested that adult men are generally less likely to seek out preventative services and health providers than adult women. An interesting counterdevelopment in Johnson County is that HPV vaccination in local school campaigns has been more successful with young boys than with young girls. The interviewee admitted that in the very conservative community, the parents of young girls are hesitant to allow their children to be vaccinated for fear that it will encourage early sexual activity. Although this is a small triumph for the participation of males in cancer prevention measures, this describes the behavior of male children in cancer prevention services and not male adults (personal communication, Teresa Lawson, Johnson County Health Department, 2/13/2013).

In Martin County, it was confirmed that both men and women are targeted for colorectal cancer screenings. However, it has been more difficult to attract men than women to the services. It was the belief of the representative that colorectal cancer is a challenging cancer to approach, especially with men, because of the fear and embarrassment that is evoked by the intimate nature of the screening procedure (personal communication, Penny Dye, Martin County Health Department, 2/11/2013). In Bell County, they are having the same issue in promoting colon cancer screening for men. In fact, they are hardly seeing men at all for those services (personal communication, Jessica Mills, Bell County Health Department, 2/26/2013).

\section{The Problem of Apathy}

According to the Director of the Whitely County Health Department, the greatest obstacle to cancer screening and prevention is no longer access to care. Instead, there is a troubling mindset of not wanting to be screened. In the Director's opinion, this is a problem that 
can be seen across almost all public health department initiatives and programs, from STDs to smoking cessation. People tend to assume that preventive services are unnecessary wastes of time and money, especially when it is difficult to observe quick and obvious results. "Apathy is an overriding issue in southeastern Kentucky (personal communication, Gail Timperio, Whitely County Health Department, 2/11/2013).” For cervical cancer, it has been clearly shown that improvements in screening outreach and extension of funding for free or subsidized treatment options have been successful. However, for future endeavors, the apathy of southeastern Kentucky citizens will need to be addressed.

\section{Return to Geospatial Methods}

All 12 health departments confirmed that they had cervical cancer screening and prevention services covering all 21 counties. The Big Sandy, Cumberland Valley, and Kentucky River ADDs had an overall decrease in cervical cancer mortality between 1995-1999 and 20052009. Going back to county-level data, however, we can see that some individual counties within those districts actually had increases in cervical cancer mortality. The most common barriers reported for those counties were transportation and lack of funding to extend services (Table 9).

Table 9: Kentucky Counties with Increases in Cervical Cancer Mortality, Percent Change between 1995-1999 and 2005-2009

\begin{tabular}{|c|c|c|} 
Name of County & $\begin{array}{c}\text { Percent Change in } \\
\text { Mortality }\end{array}$ & Most Frequently Reported Barrier via Interviews \\
\hline Harlan* & $+100.26 \%$ & Lack of funding to extend services \\
\hline Knox & $+24.33 \%$ & Transportation \\
\hline Magoffin & $+13.46 \%$ & Lack of funding to extend services; Transportation \\
\hline Wolfe* & $+141.01 \%$ & Transportation \\
\hline
\end{tabular}

* - The cervical cancer mortality rates for Harlan and Wolfe Counties were slightly unstable due to the small number of deaths within such small population centers (KCR 2012).

Table 8 listed the extent to which prostate services were offered in each health department. Only two counties claimed to offer prostate cancer screening services (Floyd and 
Pike Counties, denoted by Y/N). Of the remaining 19 counties, nine had notable successes of non-health department affiliated screening services (like Laurel County, denoted by N/Y) while 10 didn’t reference any services at all (like Bell County, denoted by N/N). An ANOVA was performed to see if the reported presence of prostate cancer screening services correlated with greater decreases in mortality (Table 10).

Table 10: ANOVA of Percent Change in Mortality between Health Departments with No Services (N/N), No Services but Addressed in Other Ways (N/Y), and Provided Services (Y/N)

\begin{tabular}{|c|c|c|c|c|c|c|}
\hline \multicolumn{7}{|l|}{ SUMMARY } \\
\hline Groups & Count & Sum & Average & Variance & & \\
\hline $\mathrm{N} / \mathrm{N}$ & 10 & -248.34 & -24.834 & 2437.87 & & \\
\hline$N / Y$ & 9 & -219.21 & -24.3567 & 1234.043 & & \\
\hline $\mathrm{Y} / \mathrm{N}$ & 2 & -40.57 & -20.285 & 92.34405 & & \\
\hline \multicolumn{7}{|l|}{ ANOVA } \\
\hline Source of Variation & SS & $d f$ & $M S$ & $F$ & $P$-value & F crit \\
\hline Between Groups & 34.89461 & 2 & 17.4473 & 0.009843 & 0.99021 & 3.554557 \\
\hline Within Groups & 31905.52 & 18 & 1772.529 & & & \\
\hline Total & 31940.42 & 20 & & & & \\
\hline
\end{tabular}

The same was performed on incidence rates (Table 11).

Table 11: ANOVA of Percent Change in Incidence between Health Departments with No Services (N/N), No Services but Addressed in Other Ways (N/Y), and Provided Services (Y/N)

\begin{tabular}{|c|c|c|c|c|c|c|}
\hline SUMMARY & & & & & & \\
\hline Groups & Count & Sum & Average & Variance & & \\
\hline$N / N$ & 10 & 20.54 & 2.054 & 578.1901 & & \\
\hline$N / Y$ & 9 & 98.79 & 10.97667 & 694.5893 & & \\
\hline $\mathrm{Y} / \mathrm{N}$ & 2 & 54.43 & 27.215 & 390.0425 & & \\
\hline ANOVA & & & & & & \\
\hline Source of Variation & SS & $d f$ & $M S$ & $F$ & P-value & F crit \\
\hline Between Groups & 1170.147 & 2 & 585.0733 & 0.944473 & 0.40733 & 3.554557 \\
\hline Within Groups & 11150.47 & 18 & 619.4704 & & & \\
\hline Total & 12320.61 & 20 & & & & \\
\hline
\end{tabular}


According to the p-values, which all happen to be much greater than 0.05 , there was no correlation between reported presence of prostate cancer screening services and greater decreases in mortality and incidence rates. Perhaps a better analysis of prostate screening via collection of data from other health clinics and local urologists would be helpful in confirming a correlation in a future study.

\section{Spatial Autocorrelation}

ArcGIS county boundary shapefiles with corresponding disease rates were used with GeoDa software to examine spatial autocorrelation and identify potential disease clusters. Spatial autocorrelation statistics are used to measure and analyze the degree of dependency among various observations in a geographic region. This concept is based on the understanding that spatial objects relate to each other and are similar and tend to cluster together (GeoDa 2013). One common global spatial autocorrelation statistic is the Moran’s Index; "global” meaning that it looks over the entire study area. Moran’s Index tests with univariate data such that a value between -1 and +1 indicates whether or not a data set is clustered (+1), random $(0)$, or dispersed $(-1)$. For the percent change in incidence rates, both cervical cancer and prostate cancer have a Moran’s Index that indicates an overall random distribution. For percent change in mortality rates, prostate cancer has a stronger value towards evenly dispersed, whereas cervical cancer is slightly clustered (Table 12). According to the p-values, the Moran's Index based on percent change in prostate mortality is statistically significant.

Table 12: Moran's Index Values for LISA Results

\begin{tabular}{|c|c|c|}
\hline Cancer Site & $\begin{array}{c}\text { Moran's Index based on \% } \\
\text { Change in Incidence }\end{array}$ & $\begin{array}{c}\text { Moran's Index based on \% } \\
\text { Change in Mortality }\end{array}$ \\
\hline Cervical & -0.00269605 (p-value 0.234) & 0.114556 (p-value 0.113) \\
\hline Prostate & -0.0919593 (p-value 0.418) & -0.264047 (p-value 0.031) \\
\hline
\end{tabular}


Globally, these results do not show strong clustering or dispersion, but they are consistent with the conclusions drawn from the qualitative data that prostate cancer improvement is rather dispersed and not correlated with public health department actions, while local cervical cancer improvement may correspond with program success.

After considering global clustering, Local Index Spatial Autocorrelation (LISA) was used to see if there were any significant clusters at the local level, or within certain sections of the study area. The generated maps indicate the absence or presence of spatial clusters or outliers. The aim was to look for improvement by how much mortality had decreased over time. Areas of least concern are indicated in blue, having the greatest decrease in mortality rates and the most improvement. Areas of most concern are indicated in red, having the least improvement.

Figure 8: LISA Map of Cervical Cancer Percent Change in Incidence Rate

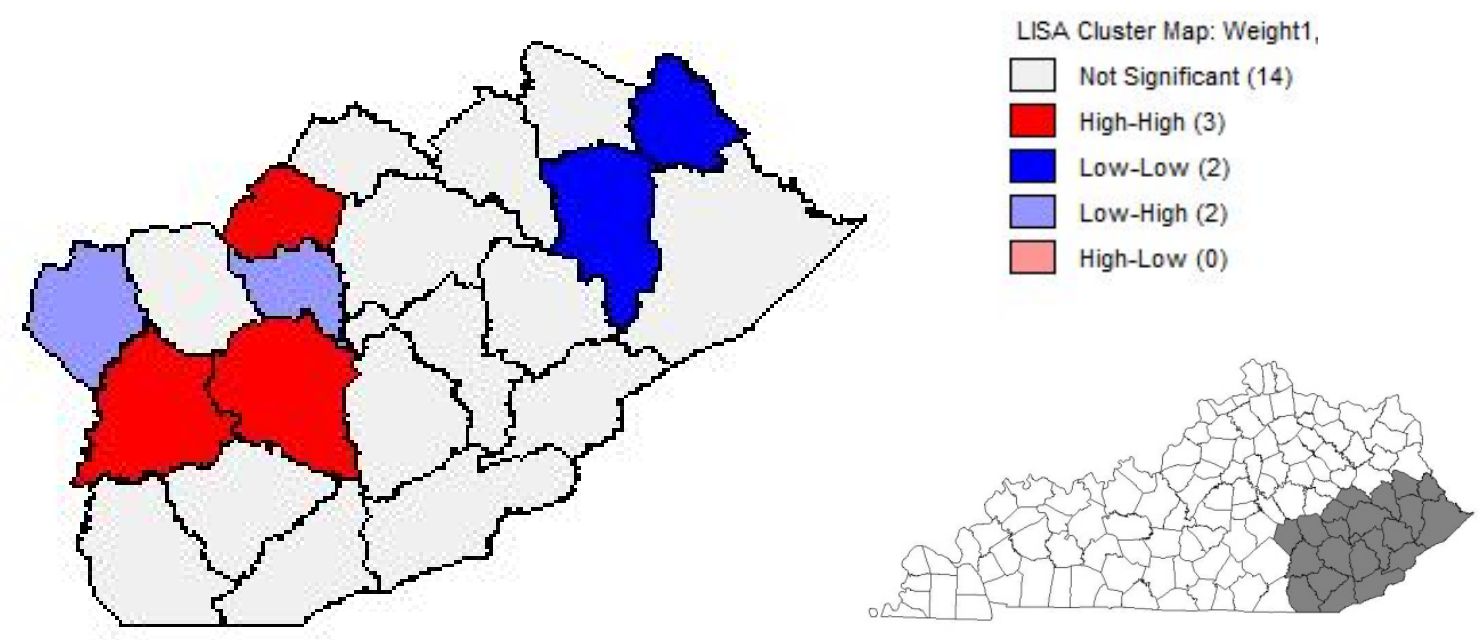

Figure 8 shows the percent change of incidence of cervical cancer, and shows two clusters: a cluster of greater decreases in Floyd and Martin Counties and smaller decrease in the counties of Lee, Clay, and Laurel (Figure 8). Although clustered in proximity, Lee, Clay, and Laurel counties were all under the umbrella of different public health departments. 
Figure 9: LISA Map of Cervical Cancer Percent Change in Mortality Rate

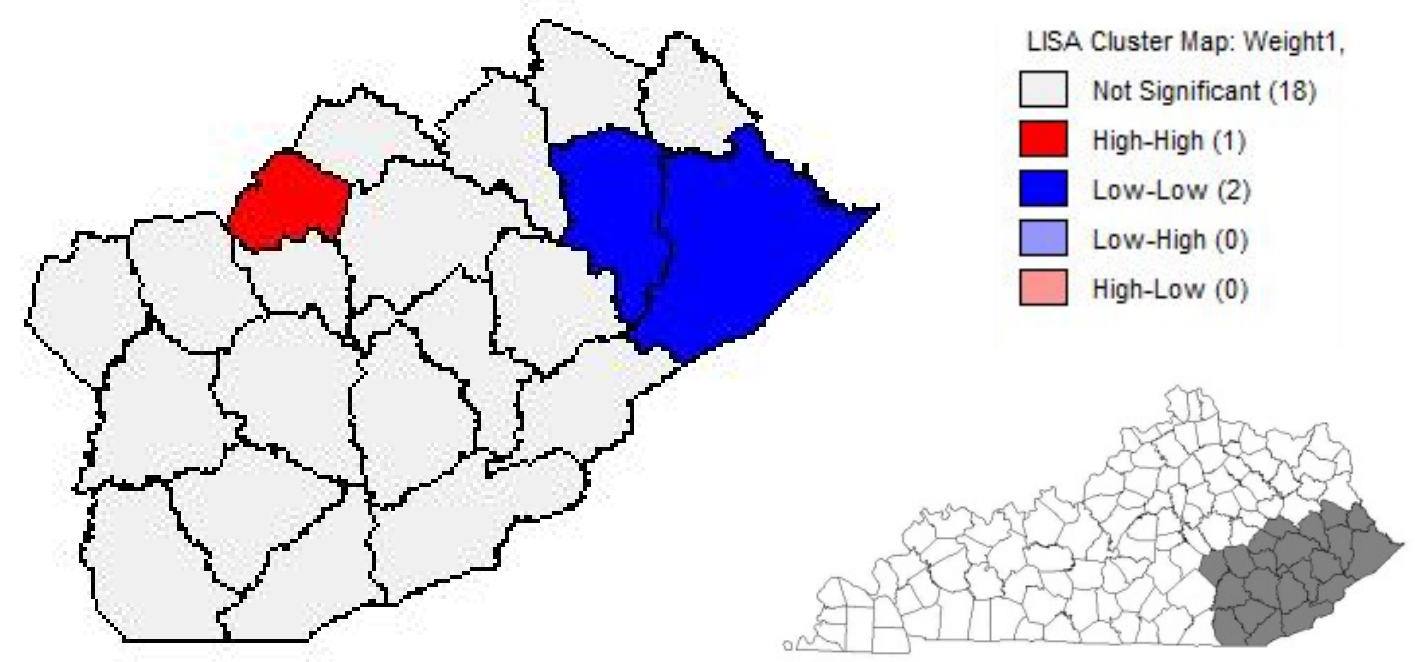

Figure 9 used the percent change of mortality of cervical cancer, and shows two clusters: a cluster of greater decreases in Floyd and Pike Counties and smaller decrease in Lee (Figure 9). One might consider from the cluster of Floyd and Pike counties that both noted the positive effect of service expansion within the past 20 years and how that has enabled many underserved women to get Pap smears when they would have never been able to get them otherwise. Counties more to the west, such as Lee, which is under the umbrella of the Kentucky River District Health Department with lots of support and resources, is a much larger department that may have had its greatest successes prior to the time frame studied. Further analyses are needed to properly correlate a specific program or strategy to the clusters. 
Figure 10: LISA Map of Prostate Cancer Percent Change in Incidence Rate

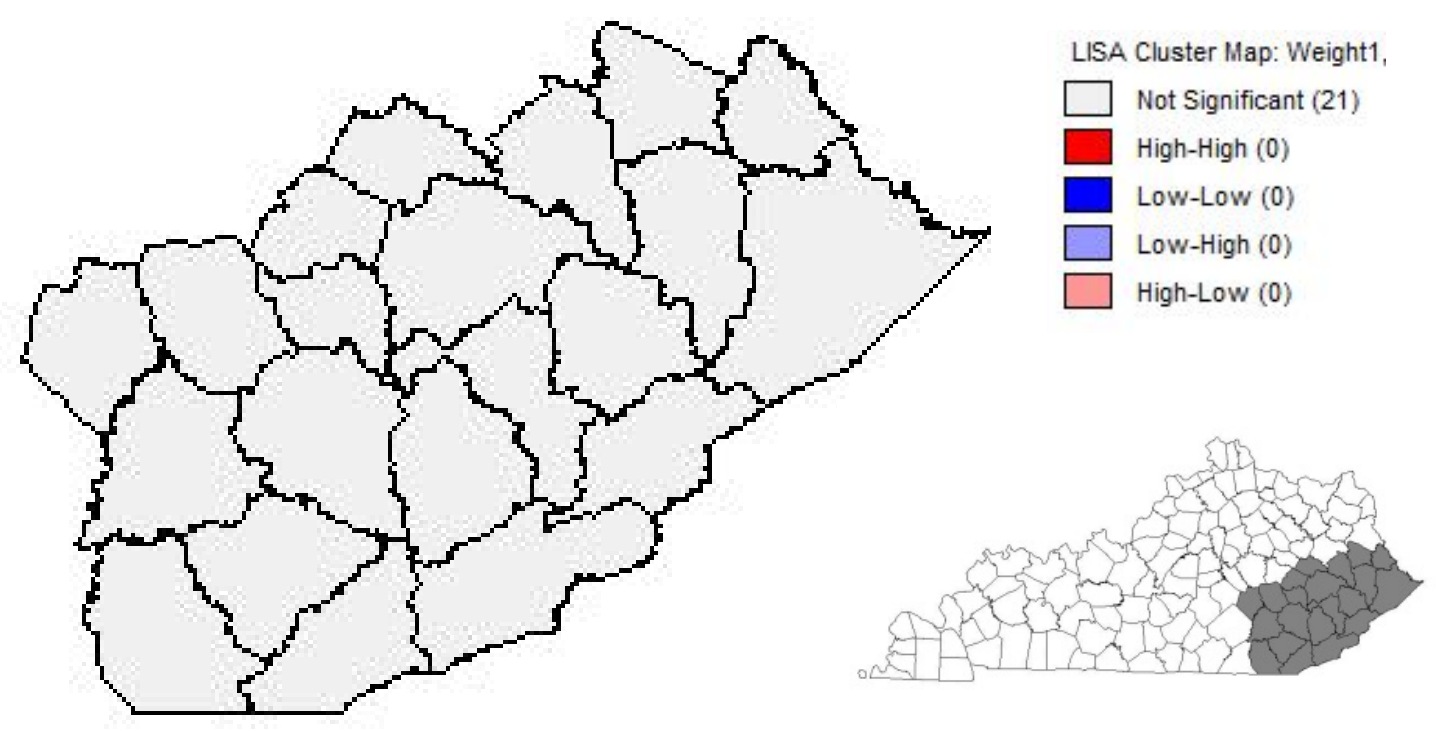

For prostate cancer data, Figure 10 showed the percent change of incidence, which showed no patterns of clustering (Figure 10). This means the change in incidence rates of the counties were relatively random. 
Figure 11: LISA Map of Prostate Cancer Percent Change in Mortality Rate

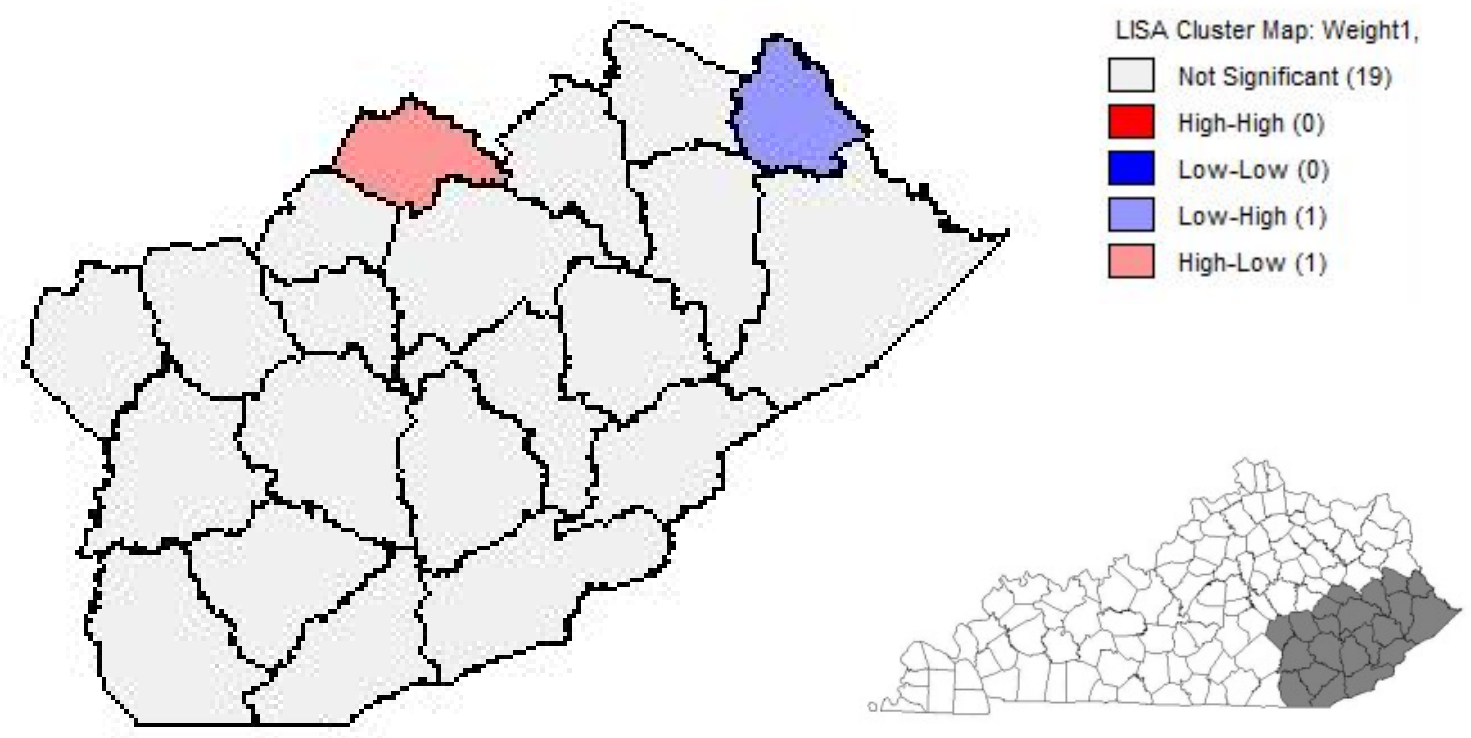

Figure 11 looked at mortality, which only showed outliers of Martin County having a greater decrease in mortality rates amongst adjacent counties with a smaller decrease and Lee having a much smaller decrease in mortality rates amongst adjacent counties with a much larger decrease (Figure 11). From the information gathered regarding the presence of prostate services in those two counties, no conclusions can really be drawn except the fact that Lee County having reportedly effective non-department affiliated PSA-test programs did not bear at all on helping to decrease mortality rates relative to other counties. The same applies to Martin County in that it was able to have success relative to the surrounding counties without any reported presence of community PSA test services.

Trends in Incidence vs. Mortality Rates

Finally, using the information extracted from the qualitative methods, the study returned to incidence rates. Mortality rates were the major focus of the study because a decrease in mortality rates indicates less death attributed to the disease, putatively the result of catching cancer in its earlier stages for more effective treatment and overall developments in better 
treatments. Looking back to Table 7, the percent change in mortality decreased for both cervical and prostate cancer between the two periods 1995-1999 and 2005-2009 (Table 7). For percent change in incidence, however, there was a decreased incidence for cervical cancer and an increase in prostate cancer (Table 13).

Table 13: Percent Change in Incidence for Selected Area Development Districts

\begin{tabular}{|c|c|c|}
\hline \multicolumn{2}{|c|}{ Percent Change in Age-Adjusted Incidence Rates in Appalachian Kentucky } \\
& (1995 -1999 to 2005 -2009) & Prostate \\
\hline Area Development District & Cervical Cancer & $8.49 \%$ \\
\hline Big Sandy & $-66.53 \%$ & $3.25 \%$ \\
\hline Cumberland Valley & $-14.17 \%$ & $12.44 \%$ \\
\hline Kentucky River & $-42.44 \%$ & (KCR 2012)
\end{tabular}

However, in the qualitative part of the study, it was clear that public health departments were much more dedicated in increasing access to cervical Pap smears than PSA tests. If more Pap smears are being performed because of an extension of public health department services and this leads to a decrease in mortality rates, why wouldn't incidence be increasing as well? An explanation for this difference lies in the fact that abnormal cervical Pap smears often indicate the presence of pre-cancerous cells, which leads to fast action and successful removal of those cells before cancer even begins. In contrast, the PSA test only works because the presence of the antigen itself is a sign that something may already be wrong with the prostate, which can lead to a complete cancer diagnosis even in its early stages. For this reason, Pap smears are a much more effective preventive screening method than PSA tests and this has led to a decline in cervical cancer diagnoses (and, therefore, in incidence rates) because of their ability to screen for problems in the precancerous stage. 


\section{DISCUSSION}

The decrease in age-adjusted mortality of cervical and prostate cancers in southeastern Kentucky implied that efforts to provide screening and treatment have been successful for both cancer sites. To better understand what those efforts have been, staff members of 12 health department covering all 21 counties in the defined southeastern Kentucky region were interviewed. In this study, several reasons were proposed for cervical cancer successes. However, the general consensus was that prostate cancer is not a primary focus of southeastern Kentucky public health departments. There is little to no funding allocated for such services at the health department level, and the focus seems to be concentrated in the private sector, if at all. Effective Strategy - The Power of Groups

Effective strategies often harness the power of group solidarity. For cervical cancer, events like Ladies Day where women can come together and participate in health promotion and prevention activities have been quite successful. For prostate cancer, “well visits’ within the workplace appear to provide positive social cohesion and support among co-workers to take part in otherwise seemingly solitary and embarrassing medical situations.

\section{Limitations in Department Funding}

It was consistent from the information gathered through the interviews that the southeastern Kentucky public health departments had little to no funding available for prostate cancer screening and prevention in comparison to cervical cancer, which happened to receive a lot of funding and support from both state and federal levels. Funding allocation favors preventative measures that are well-documented and publically accepted. Until prostate cancer research secures a more definitive screening test and uncovers a better understanding of its etiology, it is unlikely that more public funding will be spent on such services. Also, because of 
cervical cancer's label as a disease of disparity, there is more urgency to address it in southeastern Kentucky. Public health departments have to prioritize their initiatives, and prostate cancer just doesn't garner that type of support at this time.

\section{Policy Changes Often Cause Confusion}

The Pap smear is a very effective and reliable screening method for cervical cancer. Even when something as solid and publically-supported as the Pap smear undergoes new USPSTF recommendations, confusion can ensue. It can disrupt established visit routines by patients, as was observed in the Johnson and Breathitt County Health Departments. For prostate cancer, the PSA test is now recommended against by the USPSTF. Misleading and contradicting medical information can spread quickly and ultimately deter men from pursuing those services. It is still very important for health providers to educate men about the benefits and risks involved and seek out other screening methods, such as the DRE. However, the lack of overall reliability for wide-spread use of PSA tests and a confused public adds up to an unfortunately erratic climate for secured public funding and established programs put forth by public health departments. Until better screening methods and clearer preventative measures are developed for prostate cancer, the potential for effective screening and prevention at the population-level does not appear to be within sight. 


\section{FINAL CONSIDERATIONS}

The results of this small study prompt various other concerns that might be of academic and practical interest. One study that may be needed for us to properly understand how prostate cancer screening and prevention is being handled in southeastern Kentucky is to gather information on screening trends from the private sector, since that appears to be where prostate cancer screening is most extensive. In addition, now that colorectal cancer is becoming a more wide-spread focus of Kentucky public health departments, it would be very interesting to compare the differences in screening reception between southeastern Kentucky males and females. By looking at one screening method of one cancer that both genders experience with similar risk factors, we may be able to shed some light on specific barriers that men may encounter in coming in and taking advantage of those publicly-funded services. 


\section{BIBLIOGRAPHY}

American Cancer Society. 2013. Cancer Facts \& Figures 2013. Atlanta: American Cancer Society. Available at:

http://www.cancer.org/acs/groups/content/@epidemiologysurveilance/documents/docum ent/acspc-036845.pdf

Appalachian Regional Commission. 2008. Underlying Socioeconomic Factors Influencing Health Disparities in the Appalachian Region: Final Report, Contract No. CO-15198. Mary Babb Randolph Cancer Center/Office for Social Environment and Health Research. Available at: http://www.arc.gov/research/researchreportdetails.asp?REPORT_ID=9

CDC. 2012. Centers for Disease Control and Prevention. Available at: www.cdc.gov

Fischer, J.L. 2008. Cancer-related Disparities among Residents of Appalachia Ohio. Journal of Health Disparities Research and Practice, 2:2, 61-74

GeoDa 2013. GeoDaTM, version 0.9.5-i(Beta). Trademark of Luc Anselin, Spatial Analysis Lab, University of Illinois. Available at: https://geodacenter.asu.edu

KCC. 2012. Kentucky Cancer Action Plan. Kentucky Cancer Consortium. Available at: www.kycancerc.org/ActionPlan.htm

KCADD. 2009. Kentucky Council of Area Development Districts Map. Available at: http://www.kcadd.org/District_Contacts.html

KCR. 2012. Kentucky Cancer Registry. Available at: http://web.kcr.uky.edu

KYCHFS. 2010. Kentucky Cabinet for Health and Family Services. Available at: http://chfs.ky.gov

National Cancer Institute. 2012. Physician Data Query. NCI 2012. Available at: http://www.cancer.gov/cancertopics/pdq/screening/overview/patient/page1

National Cancer Institute. 2012. SEER Stat Fact Sheet. NCI 2012. Available at: http://seer.cancer.gov/statfacts/html/all.html

Oliver, J.S., Grindel, C.G., De Coster, J., Ford, C.D., and Martin, M.Y. 2011. Benefits, Barriers, Sources of Influence, and Prostate Cancer Screening Among Rural Men. Public Health Nursing, 28:6, 515-522

Roden, R. and Wu, T.C. 2006. How will HPV Vaccines affect cervical cancer? Nat Rev Cancer. 6:753-763. 
RPCI, 2010. PSA and the PSA Test: What the Public Needs to Know. April 2010. Roswell Park Cancer Institute. Available at: http://www.roswellpark.org/media/news/psa-and-psa-testwhat-public-needs-know

Schoenberg, N.E, Hatcher, J., and Dignan, M.B. 2008. Appalachian Women's Perceptions of Their Community's Health Threats. Journal of Rural Health. 2008 ; 24(1): 75-83.

Smith, R. A., Cokkinides, V., Brooks, D., Saslow, D., Shah, M. and Brawley, O. W. 2011. Cancer screening in the United States, 2011. CA: A Cancer Journal for Clinicians, 61: 830.

USPSTF. 2012. Screening for Cervical Cancer, Topic Page. April 2012. U.S. Preventive Services Task Force. Available at: http://www.uspreventiveservicestaskforce.org/uspstf/uspscerv.htm

USPSTF. 2012. Screening for Prostate Cancer, Topic Page. U.S. Preventive Services Task Force. Available at: http://www.uspreventiveservicestaskforce.org/prostatecancerscreening.htm 


\section{APPENDICES}

Appendix I: Interview Questions:

Professional Background:

1. What is your position with the County Health Department?

2. How long have you held your position?

3. Tell me about your educational and professional background.

4. Have you ever worked in a public health-related position in another county?

Health Department Services and Initiatives

1. In _ County, can you think of any specific changes or improvements in program strategies over the past 20 years that might account for the decrease in cervical cancer mortality?

2. In _ County, can you think of any specific changes or improvements in program strategies over the past 20 years that might account for the decrease in prostate cancer mortality?

Successes and Barriers

1. What are the most difficult challenges in cervical cancer screening and prevention?

a. What has the Health Department tried to overcome those challenges?

2. What are the most difficult challenges in prostate cancer screening and prevention?

a. What has the Health Department tried to overcome those challenges?

3. In your opinion, what is the biggest difference between addressing cervical cancer and prostate cancer in __ County?

4. Does the Department have any data regarding cancer screening behaviors for pap smears, PSA tests, or Digital Rectal Exams?

5. Are there specific barriers that southeastern Kentucky males face in prostate cancer screening and prevention?

a. Why is prostate cancer different from cervical cancer in this respect?

6. (If not already addressed) How do gender/socioeconomic status/level of education affect cervical and prostate cancer outcomes? 